Exploring opportunities for developing intercultural competence through intercultural communicative language teaching (ICLT): A case study in a Chinese as a foreign language classroom in a New Zealand high school

\author{
By \\ Juliet Vicary Kennedy
}

\begin{abstract}
A thesis
submitted to the Victoria University of Wellington

in fulfillment of the requirements for the degree of

Master of Arts

in Applied Linguistics
\end{abstract}

Victoria University of Wellington

2016 


\section{Exploring opportunities for developing intercultural competence through intercultural communicative language teaching (ICLT): A case study in a Chinese as a foreign language classroom in a New Zealand high school}

Abstract

This qualitative case study explores naturally arising opportunities for developing intercultural competence through intercultural communicative language teaching (ICLT) in a New Zealand high school Chinese as a foreign language (CFL) classroom. Although developing intercultural competence is a goal of many school curriculums, teacher awareness and implementation of effective intercultural pedagogies is not yet well established. Exploring the naturally arising occurrences of intercultural teaching practices and behaviours in one classroom with no formal knowledge of ICLT provides evidence of how culture may be currently understood and approached in comparative settings. Existing views on culture provide a starting point for further developing ICLT.

Data collection methods included classroom observations, stimulated recall, unstructured and semi-structured interviews, and written reflections. One teacher and three students from an intermediate level CFL class participated in the study from June to September 2015.

The findings show that while some intercultural pedagogies and behaviours occurred naturally, without an explicit focus on developing intercultural competence students are unlikely to develop the skills, attitudes, and traits which make up intercultural competence in the language classroom. This study suggests that the current cultural activities in class could be transformed into opportunities for developing intercultural competence by adding a regular comparative, connective, and reflective dimension, incorporating the students' linguistic and cultural experiences. The results of this study illustrate the necessity of expanding teacher awareness and skills in practising ICLT to promote the development of intercultural competence and to increase students' interest in learning languages in New Zealand. 


\section{Acknowledgements}

I would like to thank Catherine, Samantha, Lucy, and Kelly for giving up their time and sharing their opinions and ideas with me for the purpose of this study. My sincerest gratitude goes to my supervisor Dr Corinne Seals for the continuous wisdom, time, and support she provided me with throughout this research project. 
Table of Contents

INTRODUCTION

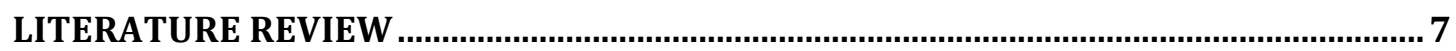

UNDERSTANDING INTERCULTURAL COMPETENCE ………................................................................. 7

INTERCULTURAL COMMUNICATIVE COMPETENCE AND INTERCULTURAL COMMUNICATIVE

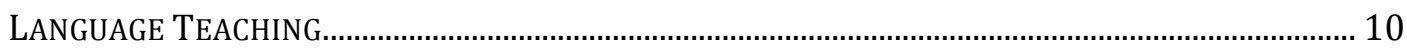

ICLT IN POLICY AND CURRICULUM DESIGN ........................................................................................... 13

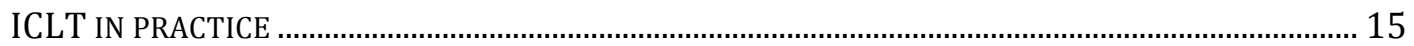

PRIOR STUDIES EXAMINING ICLT IN PRACTICE ………….............................................................. 20

ICLT OPPORTUNITIES IN CHINESE AS A FOREIGN LANGUAGE CLASSES ............................................... 23

RATIONALE FOR THE RESEARCH AND RESEARCH QUESTIONS ......................................................... 28

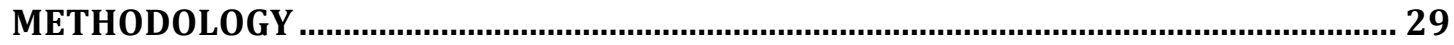

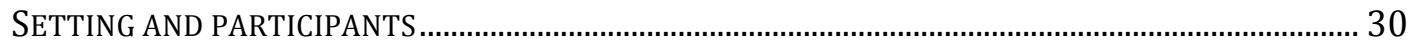

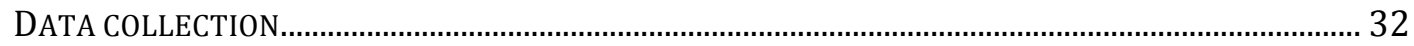

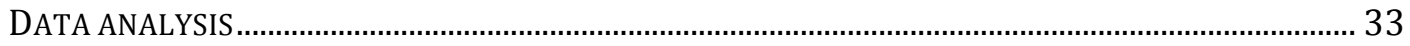

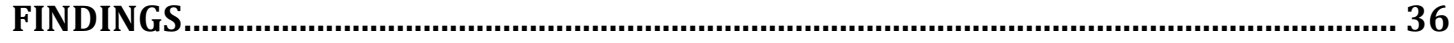

ICLT PRINCIPLE 1: ICLT INTEGRATES LANGUAGE AND CULTURE FROM THE BEGINNING ................. 36

ICLT PRINCIPLE 2: ICLT ENGAGES LEARNERS IN GENUINE SOCIAL INTERACTION N............................ 45

ICLT PRINCIPLE 3: ICLT ENCOURAGES AND DEVELOPS AN EXPLORATORY AND REFLECTIVE APPROACH TO CULTURE AND CULTURE IN LANGUAGE …….............................................................. 49

ICLT PRINCIPLE 4: ICLT FOSTERS EXPLICIT COMPARISONS AND CONNECTIONS BETWEEN

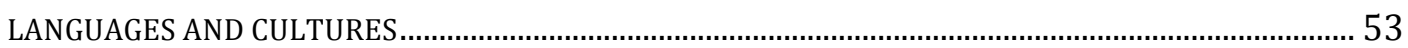

ICLT PRINCIPLE 5: ICLT ACKNOWLEDGES AND RESPONDS APPROPRIATELY TO DIVERSE LEARNERS

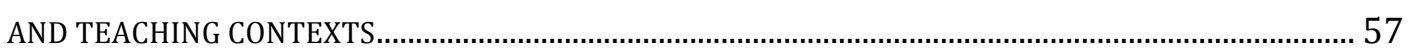

ICLT PRINCIPLE 6: ICLT PRINCIPLE 6 EMPHASISES INTERCULTURAL COMPETENCE RATHER THAN

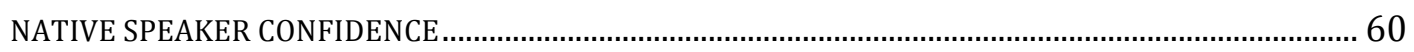

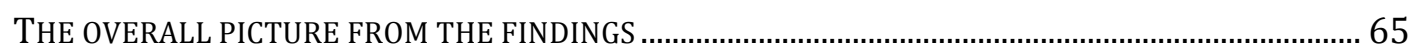

DISCUSSION

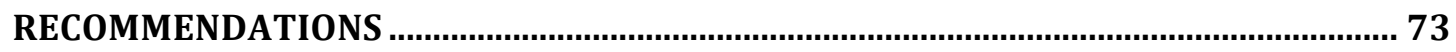

LIMITATIONS

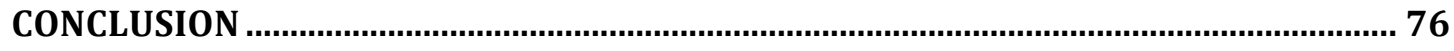

REFERENCES

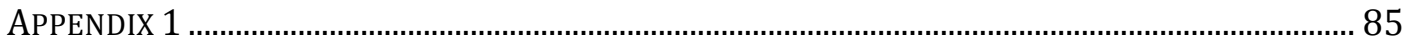

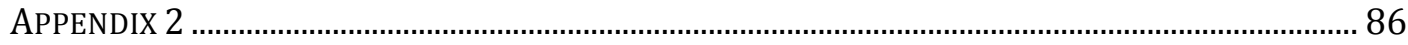

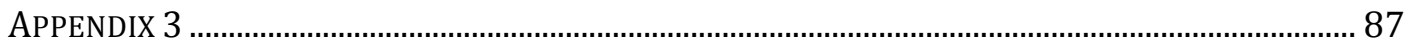




\section{INTRODUCTION}

Intercultural competence, being able to interact and communicate effectively across cultural boundaries (Byram, 1997), has become a necessary skill for successful living in an increasingly multicultural, interconnected world. Developing intercultural competence in primary and secondary school education is now a major goal of school curriculums throughout the world (Byram \& Parmenter, 2012, Sercu, 2010). In light of its rise in prominence, the literature regarding the theory and development of intercultural competence in education, and specifically foreign language education, has significantly increased over the past two decades. As a result of this, foreign language curriculum documents widely state that foreign language teaching and learning involves developing intercultural communicative competence, no longer just communicative competence in the target language (Asia Society, 2015; Bolstad, Hipkins, \& Stevens, 2013; Byram \& Parmenter, 2012, Liddicoat \& Scarino, 2010; Te Kete Ipurangi, Ministry of Education, 2015; Sercu, 2006).

Although the theory and study of the intercultural dimension in language education so far has considerably advanced the understanding of intercultural competence, research has shown that awareness of the intercultural approach is low amongst language teachers, and the understanding of how and what to teach in order to develop intercultural competence in the classroom is not well understood either (Conway, Richards, Harvey, Roskvist, 2010; East, 2012; Liddicoat, 2011, 2014; Oranje, 2013, 2014; Perry \& Southwell, 2011; Sercu, 2006).

One of the language teaching contexts for which this is particularly true is that of Chinese as a foreign language (CFL). In the context of teaching CFL, the development of intercultural skills for foreign language speakers of Chinese is pertinent in today's world. Chinese speaking communities are growing internationally, many countries are focused on developing stronger diplomatic and economic relations with China, and China is equally eager to strengthen its international ties. In the New Zealand context, the 2013 census reported a 16\% growth in Chinese immigrants since 2006 (Statistics New Zealand, 2013). According to Statistics New Zealand, many of the migrants from China are on 
student visas (Statistics New Zealand, 2013). As such, New Zealand students are highly likely to be working and studying with Chinese classmates. Therefore, young people in particular need the skills to understand and communicate effectively with classmates who have come from different backgrounds. Several studies have shown that intercultural interactions between CFL speakers and Chinese native speakers lack intercultural understanding (Tian \& Lowe, 2014; Yang, 2009; Zhou \& Li, 2014). Consequently, problems are experienced by both native speakers and CFL students.

In order to understand the practical application of intercultural theory in the language classroom, this case study explores the opportunities for developing intercultural competence through intercultural communicative language teaching (ICLT) in a Chinese $^{1}$ as a foreign language (CFL) classroom at a New Zealand high school. This thesis situates the current study in existing theories and research in the field of ICLT before discussing the findings and recommendations based on data collected from classroom observations, interviews and stimulated recall. It argues that an explicit adoption of intercultural pedagogies is required in order to provide opportunities for students to develop intercultural competence in the language classroom. The findings from this study reiterate the need for increasing teacher awareness and understanding of ICLT and provide teachers and researchers with examples of how an intercultural dimension might be incorporated into different types of existing class tasks and activities.

${ }^{1}$ Chinese in this case refers to Mandarin Chinese. 


\section{LITERATURE REVIEW}

In the present section, the theories of intercultural competence and intercultural communicative competence are examined in order to operationalise both constructs. Additionally, research in developing teacher understanding and implementation of ICLT, and ICLT in the field of CFL are reviewed before introducing the research questions. It is important to note that across the literature, intercultural competence can be referred to as: "international capabilities", "cross-cultural competence", "global competence", and /or "international mindedness." These synonymous phrases are clearly relayed in the Ministry of Education International Capabilities report ${ }^{2}$. This study uses the most commonly used term in the literature - "intercultural competence."

\section{Understanding Intercultural Competence}

Intercultural competence is a "general humanistic educational goal" (Sercu, 2010, p. 17) which aims to develop "the ability to communicate and interact across cultural boundaries" (Byram, 1997, p. 7). Many education systems and employers internationally acknowledge the value and necessity of developing intercultural competence in today's world, due to the fact that societies are increasingly multicultural and multilingual (e.g. Byram \& Parmenter, 2012; Te Kete Ipurangi, Ministry of Education, 2015; Scrimgeour \& Wilson, 2009; Sercu, 2010). An intercultural view in teaching and learning across curriculum areas is now widely required and expected, as shown in the excerpt below from support resources available to help teachers enact the New Zealand Curriculum:

International capabilities are the knowledge, skills, attitudes, dispositions, and values ... that enable people to live, work, and learn across national and cultural boundaries... Being internationally capable includes not only the awareness of other cultures, but also the awareness of one's own culture as particular and specific. It involves the understanding that we all experience our lives through a number of cultural and personal "lenses", and that

\footnotetext{
${ }^{2}$ https://www.educationcounts.govt.nz/publications/international-capabilities.
} 
comprehending and accepting others' needs and behaviours rests as much on understanding ourselves as it does on understanding them.

(Te Kete Ipurangi, Ministry of Education, 2015)

The above definition of intercultural competence, (referred to as "international capabilities") in the New Zealand Curriculum (2015) is well aligned with other definitions found in global curriculum documents and research (e.g Asia Society, 2015; Bolstad et al, 2013; Byram, 1997; Chen \& Starosta, 1998; Liddicoat \& Scarino, 2013).

Given the New Zealand context, the definition of intercultural competence from the New Zealand Curriculum will form the baseline definition for this study. The four general domains of intercultural competence (knowledge, skills, attitudes, and traits or dispositions) need to be interpreted with two key points in mind. Firstly, from the intercultural perspective, culture should be seen as culture as social practice - a complex and dynamic framework in which individuals may share some common practices based on a "native cultural blueprint" but also bring their own personal experiences and understandings of life (Liddicoat \& Scarino, 2013, p. 23). The second point imperative to developing intercultural competence is the need to discover and understand one's own culture as one learns how to relate to otherness (Liddicoat \& Crozet, 2001). Considering these two points, I look to the literature in the field of ICLT to expand on the definition of intercultural competence in the New Zealand curriculum below.

Byram (1997), Chen \& Starosta (1998), and Liddicoat \& Scarino (2013) provide further insight helpful to gaining a deeper understanding of the definition of intercultural competence used in the New Zealand Curriculum. Byram's (1997) model of savoirs is regarded by researchers in the field as one of the most comprehensive and widely cited frameworks for developing intercultural competence in language education (Byram, 2014, Liddicoat, 2011; Sercu, 2006, 2010). Savoir refers to knowledge of self and others, customs and ways of interacting and provides the basis of knowledge for the intercultural learner (Liddicoat, 2011). Byram's (1997) framework incorporates four different types of savoirs required to develop intercultural competence, in addition to savoir as described above. Savoir être aims to develop an open, 
curious, and reflexive attitude to intercultural learning. Savoir comprendre involves learning how to interpret and explain cultural practices, and then compare with one's own culture. Savoir apprendre is knowing how to make discoveries through personal involvement in social interaction, and savoir s'engager is being able to critically evaluate features of one's own and others' cultures (Liddicoat, 2011). Additionally, Chen and Starosta (1998, p. 28) refer to an effective interculturalist as: interculturally sensitive (open-minded, nonjudgmental, empathetic, relaxed in social situations, and having a positive self image), interculturally aware - (culturally self-aware and knowledgeable, familiar with and sensitive to different areas in which culture affects interactions), and interculturally adroite, (equipped with good communication skills and behavioural flexibility).

Liddicoat and Scarino (2013) summarise the knowledge, skills, attitudes, and traits which make up intercultural competence as involving a minimum of the following directly quoted points:

- accepting that one's practices are influenced by the cultures in which one participates and so are those of one's interlocutors;

- accepting that there is no one right way to do things;

- valuing one's own culture and other cultures;

- using language to explore culture;

- finding personal ways of engaging in intercultural interaction;

- using one's existing knowledge of cultures as a resource for learning about new cultures;

- finding a personal intercultural style and identity.

(Liddicoat \& Scarino, 2013, pp. 23-24)

This operationalised definition of intercultural competence in education reflects the fact that intercultural competence is reflexive, interactional, complex and evolving. Although there is potential to develop intercultural competence in many school curriculum areas, the current study focuses on developing intercultural communicative competence (ICC) in foreign language education, and more specifically in CFL.

ICC is very close to intercultural competence; both involve making links, comparisons and mediating or exploring between cultures. The main point of difference is that ICC is the ability to "interact with people from another country in a foreign language" (Byram, 1997, p. 71). ICC allows a person to deal with a wider range of situations, as interactions can take place in one or more 
languages. In an educational setting, understanding and developing linguistic skills alongside cultural understanding is the main focus of ICC. ICLT is a recommended approach in language teaching for developing ICC (Liddicoat \& Scarino, 2013; Newton, Yates, Shearn, \& Nowitzki, 2010, Newton, 2014; Sercu, 2006).

\section{Intercultural Communicative Competence and Intercultural Communicative Language Teaching}

Studies on the development of ICC in language education have existed for a long time. Humboldt (1836 [1988]) foresaw the potential of foreign language learning in developing intercultural competence in his writing on Bildung (education): "to learn a foreign language should ... be to acquire a new standpoint in the worldview hitherto possessed" (Humbolt, 1836/1988, p. 60). Nearly two centuries later, the words of Humboldt resonate clearly in today's globalised world.

Despite Humboldt's foresight, the implications of his philosophy have not been realised until recently. Historically, culture has not shared equal status with language acquisition in the classroom, and has instead been taught as an adjunct to language in foreign language education. Lo Bianco, Liddicoat, \& Crozet (1999) talk about four approaches to teaching culture in language teaching history. The following list is directly quoted with extra explanations italicised:

- The traditional approach (learning about high culture, through literature)

- The cultural studies approach (learning about countries, through facts)

- The culture as practices approach (learning about typical values and practices)

- Intercultural language teaching (developing intercultural competence through foreign languages)

(as cited in Lo Bianco et al, 1999, pp. 8-11)

The first three approaches to culture have been taught separately to language. These approaches are now considered narrow and are criticised by theorists as presenting culture as static and as a finished product (Liddicoat \& Crozet, 2001; Kramsch, 1993; Liddicoat, 2008; Liddicoat \& Scarino, 2013). Research into the relationship between language and culture has increasingly seen acceptance of the notion that culture embodies all communication (Kramsch, 1993; Lo Bianco et al, 1999; Liddicoat \& Crozet, 2001). This notion is the starting point of the 
intercultural approach - that language and culture are inextricably linked, and therefore, culture and language need to be treated with an equal and integrated approach in foreign language education (Liddicoat \& Crozet, 2001; Kramsch, 1993, Lo Bianco et al, 1999).

An intercultural approach therefore no longer views language learning and teaching as a matter of acquiring a set of linguistic skills, whereby the learner 's ultimate goal is to be linguistically and culturally assimilated as a native speaker (Byram, 1997, Byram \& Parmenter, 2012; Coperías Aguilar, 2007; Kramsch, 1993; Liddicoat, Crozet, \& Lo Bianco, 1999). Intercultural communicative language teaching and learning focuses on developing communicative and intercultural competencies in parallel. Language and culture are viewed as dynamic social practices.

There are several common understandings in the literature of ICLT which are crucial to ICLT as a construct and in practice. Researchers stress that in incorporating the intercultural dimension, the basic goal of developing competent communicators in the target language has not changed. ICLT still upholds language knowledge as a core focus, but the ICLT approach requires teachers to be more aware of the importance of culture and how it impacts on language learning. ICLT's predecessor, communicative language teaching, focuses on developing native speaker norms both linguistically and culturally. The aim of developing native speaker competence is now seen as an unrealistic and undesirable goal for most students (Coperías Aguilar, 2007; Liddicoat \& Crozet, 2001; Kramsch, 1993; Liddicoat and Scarino, 2013; Newton et al, 2010). Instead, the ICLT approach allows the foreign language learners to retain their "social, linguistic and cultural baggage" (Coperías Aguilar, 2007, p. 63) and prepares learners to communicate in a foreign language outside their own cultural boundaries (Liddicoat \& Crozet, 2001).

Additionally, ICLT involves both factual knowledge and experiential knowledge (Liddicoat \& Scarino, 2010; Sercu, 2010; Sfard, 1998). Sfard (1998) discusses the necessity of including the 'acquisition metaphor' (factual, objective knowledge of culture and language savoir), and the 'participation metaphor': contextual and personalised knowledge based on one's experience as a "participant member of human society" (Liddicoat \& Scarino 2010, p. 54). The 
participation metaphor requires learners to continuously be active in using prior life experience to interpret and express meaning across cultural boundaries, both with oneself and with others (e.g. savoir être, savoir comprendre, savoir apprendre). Therefore becoming intercultural is an ongoing process of reflection and action in response to new experiences (Liddicoat \& Scarino, 2010). Sercu (2004, 2010) similarly emphasises that education for intercultural competency involves enabling and encouraging young people to become life-long, selfmanaged and global minded learners. ICLT requires a "meta-cognitive dimension" (Sercu, 2004, p. 76) to enable learners to "plan, monitor, and evaluate their own learning processes" (Liddicoat, 2011, p. 840).

Another common understanding of ICLT is that ICC is not acquired via osmosis; rather it requires a conscious and explicitly taught ongoing process of intercultural comparison and exploration, for which ICLT is useful (Byram, 1997, 2014; Coperías Aguilar, 2007; Kramsch, 1993; Liddicoat \& Scarino, 2013; Liddicoat, 2014; Lo Bianco et al, 1999). Through comparing and exploring cultures, teachers can enable students to decentre from their own linguistic and cultural stand-points in order to understand the 'other' worldview or stance. In this way the 'other' is no longer perceived as strange or alien.

Researchers refer to ICLT as helping learners to become mediators between two or more cultures. As mediators, learners are trying to find a 'third space' or 'meeting place' in which they can manage the communication, interactions, and worldviews of both their own culture and the target culture (Byram, 1997, 2014; Coperías Aguilar, 2007; Kohler, 2015; Kramsch, 1993; Liddicoat \& Scarino, 2013; Liddicoat, 2014; Lo Bianco et al, 1999). Crucially, this process can only be achieved if the learners are aware of their own culture. Additionally, unity and diversity can be reconciled in this intercultural third space (Lo Bianco et al, 1999). In mediating the intercultural space, ICLT aims to teach culture in use and develop attitudes of openness and curiosity (savoir être, Byram, 1997) rather than teaching cultural stereotypes. Stereotypes both positive and negative can creative unsuccessful interactions and hinder mutual understanding (Byram, 1997).

Finally, in examining common understandings in the field of ICLT, it must be noted that the literature acknowledges it is impossible to learn all cultural 
conventions in a classroom (Byram, 1997). Byram $(1997,2014)$ argues that foreign language education is dependent on context. Therefore ICLT as an approach to foreign language education needs to consider the geo-political context, the learning context, the level of students, and the learning objectives of the curriculum (Byram, 1997, pp. 79-80).

\section{ICLT in policy and curriculum design}

The Common European Framework of Reference for Languages (CEFR) describes intercultural communicative competence as an underlying goal of language education (Byram \& Parmenter, 2012). Similarly, the International Curriculum for Chinese Language Education initiated by the Office of Chinese Language Council International (Hanban - The Confucius Institute) contains a cultural awareness component made up of four strands: cultural knowledge, cultural understandings, cross-cultural awareness, and global awareness (Scrimgeour \& Wilson, 2009). School curriculums in many countries, notably in Australia, Bulgaria, Argentina, and New Zealand (Byram, 2014), strongly support the development of intercultural communicative competence. In the most recent New Zealand curriculum first published in 2007, language and culture are equally weighted as two strands supporting the main goal of communication. The following outcomes for the cultural knowledge strand of foreign language learning are provided:

In the supporting cultural knowledge strand, students learn about culture and the interrelationship between culture and language. They grow in confidence as they learn to recognise different elements of the belief systems of speakers of the target language. They become increasingly aware of the ways in which these systems are expressed through language and cultural practices. As they compare and contrast different beliefs and cultural practices, including their own, they understand more about themselves and become more understanding of others.

(Ministry of Education, 2007, p.24)

In order to support teacher understanding and interpretation of the new strand of cultural knowledge, Newton et al (2010) were commissioned by the 
Ministry of Education to write a review of the literature surrounding intercultural language learning. This report is often referred to as "the Newton report”. In response to the literature review, Newton et al (2010) developed six principles of iCLT ${ }^{3}$ designed to help New Zealand foreign language teachers provide intercultural learning opportunities in line with the curriculum (Newton, 2014). The Newton report and principles of iCLT take into special consideration the rich resources that Te Reo Māori and Pasifika languages bring to intercultural language learning in New Zealand (Newton et al 2010, p. 63). The following list is a direct quotation. The iCLT principles state that an intercultural approach:

1. integrates language and culture from the beginning

2. engages learners in genuine social interaction

3. encourages and develops an exploratory and reflective approach to culture and culture-in-language

4. fosters explicit comparisons and connections between languages and cultures

5. acknowledges and responds appropriately to diverse learners and learning contexts

6. emphasises intercultural communicative competence rather than nativespeaker competence.

(Newton et al, 2010, p. 63, direct quotation)

Newton (2014) presented an updated version of the iCLT principles at a national level conference for foreign language teachers. This recent version of the principles has not yet been widely disseminated amongst the foreign language teachers in New Zealand. Newton's (2014) revised iCLT principles aim to focus the field of ICLT on the most recent publications and provide more practical suggestions for teachers as to how they might take an intercultural approach to language teaching.

\footnotetext{
3 The Newton principles are always notated with a lower-case 'i' - iCLT. ICLT with a capital 'I' refers generically to communicative language teaching with intercultural dimensions.
} 
The new look iCLT principles (Newton, 2014) state that the intercultural language teacher will:

\section{1. engage with the social context of learning}

a. Use culturally responsive pedagogies to make the most of diversity in the classroom, school community by recognizing and connecting to the home knowledge, languages and practices of learners.

b. Establish links beyond the classroom relevant to the ways a language is present in and beyond New Zealand. (In EFL settings: Expose learners to the diversity of world Englishes and raise awareness of English as an international language).

\section{2. focus on intercultural learning objectives}

Foster and affirm intercultural learning achievements in tandem with linguistic and communicative achievements.

\section{3. adopt intercultural classroom practices}

Provide opportunities for learners to:

a. engage with culture in and around culture from the beginning;

b. interact and communicate in the language;

c. explore, reflect on, compare and connect experiences, knowledge and understandings;

d. put learning into practice beyond the classroom, making choices and acting in interculturally informed ways.

(Newton, 2014, p. 1, direct quotation)

The original six principles of iCLT have been disseminated through professional development programmes, curriculum resource documents such as summary posters, conferences, and the Te Kete Ipurangi Ministry of Education website. Foreign language teachers in New Zealand should theoretically be aware of the construct of intercultural communicative competence and aim to incorporate the iCLT principles into their classroom practice. However, as discussed in depth below, research suggests that teacher awareness and uptake of the iCLT principles is not yet commonly found in New Zealand schools. As this thesis aims to better understand the practical application of ICLT it is important to examine the research on teacher awareness and teacher uptake of ICLT both in New Zealand and beyond before exploring the literature.

\section{ICLT in practice}

A number of recent studies in New Zealand (Conway \& Richards, 2014; Conway et al 2010, 2012; East, 2012; Oranje, 2013, 2014) suggest that foreign 
language teachers are generally unaware or unsure how to practise and interpret the cultural knowledge strand of the curriculum (Conway et al, 2010), or are unaware of ICLT and what it means for the classroom (Oranje, 2013, 2014). East (2012) provides the following hypothesis as to why teacher awareness of the intercultural approach is not as strong as teacher awareness of language acquisition pedagogy. The Ellis (2005) report on instructed second language acquisition (supporting the language knowledge strand of the curriculum) was published and disseminated widely to schools well before the introduction of the new curriculum. As a result, teachers were able to process and embed recommendations made in the Ellis report in time for the release of the new curriculum (East, 2012). In contrast, the Newton report (Newton et al, 2010) (supporting the cultural strand of the curriculum) was delayed in its publication. Apart from a short summary available in curriculum support materials, teachers were not provided with significant opportunities to envisage how intercultural language teaching might be implemented in the classroom until after the publication of the curriculum (East, 2012). The delay in its publication could arguably have disadvantaged initial teacher understanding of ICLT (East, 2012). This knowledge is important in evaluating two New Zealand studies (e.g. East, 2012; Conway et al, 2010) on teacher understanding and implementation of ICLT.

As part of an exploration of how task based language teaching (TBLT) might successfully include an intercultural dimension, East (2012) used semistructured interviews with 19 teachers to examine practitioner understanding of 'cultural knowledge' as prescribed in the New Zealand Curriculum (2007). Eight national language advisors were also interviewed in order to provide intramethod triangulation between the practical micro viewpoint of one classroom and the broad perspective of advisors overseeing language teaching in New Zealand. Data from the teacher interviews showed that teacher perceptions about culture in language education was often realised as culture as static knowledge. Culture was approached as factual knowledge with topics such as food and festivals.

Although some teachers tried to make the cultural element experiential, for example by eating German food, there appeared to be no inclusion of 
opportunities for intercultural reflection. Several teachers also took an ethnocentric view of culture, portraying the 'other' as strange. Culture was separated from language and in some cases obviously thought of as less important with one teacher referring to culture as always being "the thing you run out of time to do" (East, 2012, p. 63). However, the language advisors showed a deeper understanding of the reflexive nature and critical awareness of ICLT. In concluding, East reiterated that the report introducing the six principles of iCLT (Newton et al, 2010) had not yet been released at the time of this study. East (2012) hypothesised that as teachers became more used to the new curriculum and began to better understand ICLT through the framework of the six principles, the cultural knowledge strand promoting the intercultural dimension would gradually see languages and culture interwoven in the FL classroom. He suggested that further research might include classroom observations to strengthen the data collected from reflective interviews.

The results of East's study (2012) are comparable to the findings of a study evaluating teacher understanding of language and cultural knowledge (Conway et al, 2010). Conway et al (2010) evaluated the provision of language and cultural knowledge for 25 teachers on a Ministry of Education funded teacher professional development programme for FL teachers during 2008. Data from surveys of the 25 course participants, three observations and face-to-face interviews from seven focus teacher participants (from a variety of geographical areas, school types, teaching experience, and language ability) were collected and analysed over one year. Results showed that the participating teachers significantly increased their understanding of how to develop learner linguistic knowledge, due to the content of the programme being largely guided by a "deep principled knowledge base" (Conway et al, 2010, p. 449), namely the Ellis (2005) principles for effective instructed second language acquisition. Improved teacher understanding of cultural knowledge was deemed less successful due to a lack of "deep principled knowledge base of intercultural language teaching" (Conway et al, 2010, p. 449). None of the teachers observed was seen to provide opportunities for learners to reflect on their own culture from the viewpoint of the other or for learners to interact in target language communities (Conway et al, 2012). 
In a later publication, Conway et al (2012) acknowledge the limitations of their 2009 study, namely the small sample number (seven focus participants) taken from a cohort of one year. They suggest that data from subsequent participants of the professional development programme would shed more light on current teacher understanding and implementation of iCLT principles. Conway et al (2012) mention that several steps had been taken by the professional education programme and other supporting educational organisations since the publication of their 2009 report to address the lack of deep principled knowledge base of ICLT. Improvements in the form of dissemination of the Newton report to teachers and language immersion awards to support language and cultural learning of teachers are some measures which were put in place.

Conway and Richards (2014) have since extended their research of intercultural language teaching practices of New Zealand foreign language teachers. In 2013 they surveyed 65 teachers and focused on twelve case study teachers (Conway \& Richards, 2014). The results of their research are presented within the framework of Newton et al's (2010) iCLT Principles. Byram (2014) mentions some of their initial findings which suggested that teachers are supportive of iCLT Principle 1 (integrating language and culture from the beginning). Case study interview analysis however, suggested that the classroom practice surrounding iCLT Principle 1 depended on the individual teacher's language proficiency and experience in the target culture. More fluent speakers who had spent time living in the target culture and engaged in regular professional development tended to take a dynamic approach to teaching language and culture. Teachers with lower levels of language proficiency and less firsthand experience of the target culture tended to take a more factual and static approach in their teaching of culture.

Conway and Richards (2014) found that iCLT Principle 3 (exploring and reflecting about culture and culture-in-language) was not especially well understood and practiced by teachers. Survey data showed that whilst most teachers reported that they incorporated reflection into their lessons, further investigation revealed that reflection was commonly interpreted by teachers as making comparisons. Conway and Richards (2014) echo Liddicoat and Scarino 
(2013) in stressing that comparisons alone are not an end point to studying culture. Instead they suggest comparisons should be used as a trigger to encourage deeper thinking and reflection. Reflection might eventually bring new understanding to interaction in the target language (Conway \& Richards, 2014; Liddicoat \& Scarino, 2013).

Although Conway et al (2012) and Conway and Richards (2014) indicate that teacher understanding and practice of ICLT has received increased support from professional development programs and Ministry of Education resources and consequently is practised slightly more widely, another study (Oranje, 2013, 2014) shows that teacher understanding and implementation of ICLT continues to be limited (Oranje, 2013, 2014). In a survey study of 76 South Island New Zealand language teachers, results showed:

- $44 \%$ of teachers had not heard of ICLT

- $19 \%$ had only heard of it

- $29 \%$ were familiar with it and practised it

- $7 \%$ were familiar with it but did not practise ICLT

(Direct quotation, Oranje, 2015, personal communication)

Oranje emphasises that the survey data is based on what teachers have reported and that the data has not been verified with observations or more long-term investigation (2015, personal communication). Data from classroom observations would enhance the validity of these findings.

In all New Zealand publications (Conway \& Richards, 2014; Conway et al 2010, 2012; East, 2012; Oranje, 2013, 2014) the limitations need to be considered. The number of teachers who have regularly been observed and interviewed about their practice is small. In order to determine a clearer picture of how ICLT is actually practised in the classroom, regular observational data is required to triangulate data collected through surveys and interviews to strengthen the validity and reliability of the findings. In spite of these limitations, these studies have provided invaluable insight about teacher awareness of ICLT in New Zealand. The general picture is that ICLT awareness has increased (Conway et al, 2012, 2014), but New Zealand language teachers generally do not yet widely show understanding and evidence of practising ICLT. This reflects the results of a similar international study, discussed below. 
Sercu (2006) investigated teacher self-concepts and teaching practices of language and culture in relation to the new profile of the intercultural foreign language teacher. In addition, the study sought to speak of "an average cultureand-language teaching profile" (p. 58) which could be applicable to FL teachers in different countries. 424 secondary school teachers from Belgium, Bulgaria, Greece, Mexico, Poland, Spain and Sweden completed online surveys with mainly closed and some open questions. Statistical analysis showed that the country samples did not significantly differ. Results showed that language teachers were well equipped to teach culture in the communicative approach where the main focus is language acquisition, with some acquisition of factual knowledge of culture. Teachers generally lacked the skills for teaching intercultural communicative competence.

Sercu's (2006) study reveals that comparing cultures was frequent in language lessons but that critical reflection and exploration of the target and first culture were not practised regularly, as was the case for Conway and Richards (2014). Teachers were for the most part well disposed to the idea of teaching intercultural competence through foreign language lessons. Sercu (2006) concludes that an average culture-and-language teaching profile does exist: teachers seem to be moving towards teaching ICC, but apart from individual cases, teachers do not yet show the knowledge and skills required to teach it ( $\mathrm{p}$. 55). These results are once again similar to those in the Conway and Richards (2014) study. Sercu (2006) acknowledges that although additional qualitative data would have provided more in depth information, the logistics of collecting data through tools such as unstructured interviews would have made the international collaboration and comparison very difficult. Sercu's (2006) study is now ten years old, and more recent international studies on how teacher interpretation of ICLT has developed are needed.

\section{Prior studies examining ICLT in practice}

Though research shows that levels of teacher awareness and implementation of ICLT are low, several publications and studies provide useful insight into the practicalities of ICLT in the foreign language classroom. Early publications introducing the concepts of ICLT by Lo Bianco et al (1999) and Liddicoat and 
Crozet (2001) provide useful guidance for teachers in how to integrate language and culture from the start. They illustrate how culturally loaded simple, formulaic expressions surrounding greetings, answering the phone, or meal times can be. Liddicoat (2001) stresses that in order to develop basic intercultural understanding, language learners need to understand what native speakers mean when they use their L1.

The list bellow, directly quotes some of Liddicoat's suggested questions that teachers should consider when teaching specific linguistic structures:

- How do you start a conversation?

- What do you say when someone asks you "Did you have a good weekend?"

- What are the functions of questions such as "How are you"? Are they legitimate questions about the state of one's health or are they used as ritualised utterances? In either case what are culturally appropriate things to say in this position?

(Liddicoat, 2001, p. 60)

Skene's (2013) study of three Australian primary school classes learning French provides a good example of how to practically involve an intercultural approach to language lessons. The topic for the intercultural project was le pain et la boulangerie (bread and the bakery). Students began with watching a DVD about a young boy from Lyon talking about a day in his life, followed by a class discussion for students to make meaning of what they saw. The focus point of bread and what it represents in French culture was then introduced through photographs, and students were invited to write a reflection about one aspect of the class discussions so far in relation to themselves. After some class discussion about the reflection, students then prepared and participated in conversations set in a boulangerie. The teachers aimed to make this experience as authentic as possible by providing menu boards, complete with realistic prices and written in a style of handwriting popular in France. Performances were videoed and peerevaluated. Students wrote a final reflection on the following questions: "In your opinion, what are the differences between buying bread in Australia and in France? You may like to compare Baker's Delight (a bakery chain store in Australia and New Zealand) to a French boulangerie. Which do you prefer and why?" (Skene, 2013, p. 50). Details of this project underline how culture and language and reflection of one's own culture in relation to the target language 
and culture can be integrated into foreign language education. This type of project is adaptable to different topics and age levels. Similar projects have been discussed in various publications, notably in the fields of French, German, Indonesian, and Japanese as a foreign language (Chun, 2011; Kohler, 2015; Liddicoat, 2008, Liddicoat \& Crozet, 2001; Liddicoat \& Scarino, 2013).

Extensive searching has revealed only one publication which outlines practical implementation of ICLT in CFL. Liddicoat and Scarino (2013) present an example of how translation of texts from Chinese to English (or any language) can be done with an intercultural approach. The CFL teacher who designed the translation unit asked the following questions of the students:

- What skills are needed for translation?

- How accurate is online translation?

- How translatable are languages? What is lost in translation?

- What does it mean to "translate interculturally?"

- How important is this?

(directly quoted, Liddicoat \& Scarino, 2013, p. 70)

As part of the project, students engaged with a variety of different texts, some in Chinese, some texts mistranslated from Chinese to English, and some well translated texts. Students were also asked to explore what happens when using online translators. The final part of the project involved class discussion and individual reflections about what makes a good or a poor translation and in which ways or to what extent translation involves culture (Liddicoat \& Scarino, 2013). Analysis of student reflections and work showed that the processes involved in this unit of work provided students with the opportunity to develop ICC. Translation allowed the students to move between and compare Chinese and English. Students were also able to actively construct knowledge, make connections, and reflect during various stages of the unit.

On completion of the translation unit, the teacher commented that she saw the students decentring from their cultural norms. As an example of this decentring, the teacher mentioned one student who began the unit on translating thinking that "because of poor translation, a country or culture could get a bad reputation": at the end of the unit the student reported that she felt "less critical of people who make bad mistakes when translating" (Liddicoat \& Scarino, 2013, p. 74). Both knowledge of what was done in the unit, and the evidence of ICLT at 
work in the analysis of student work are invaluable resources for CFL teachers looking to successfully implement ICLT.

The above-mentioned studies all explore practical ways of implementing ICLT and provide teachers with useful ideas as to how one could provide opportunities for developing ICC language classes. Nonetheless, the literature is clear that current research is not reaching teachers sufficiently to make a difference (Byram, 2014; Kohler, 2015). Teacher understanding of how to practise ICLT is a major obstacle to its implementation in the classroom (Byram, Holmes, \& Savvides, 2015; Diaz, 2013; Kohler, 2015). This is particularly true in the case of CFL.

\section{ICLT opportunities in Chinese as a foreign language classes}

In the field of CFL, the cultural dimension has generally been considered important in the classroom. However, Wong (2008) comments that how culture is approached has been overlooked and under theorised in CFL. A static approach to teaching culture is prevalent in the CFL classroom (Diaz, 2013) with resources often "festooned with lanterns, dragons" and "images of the Great Wall" (Orton, 2011, p. 161), and cultural studies often viewed as a separate entity and secondary in importance to language study. Yet the need to develop intercultural communicative competence in CFL speakers is extremely important. As previously mentioned, results from the 2013 census show a large increase in Chinese immigrants to New Zealand between 2006 and 2013, with a growth rate of $16 \%$. China is the second largest source country of migrants to New Zealand (Statistics New Zealand, 2013). Statistics show that a large percentage of Chinese immigrants in New Zealand are students (Statistics New Zealand, 2013). Therefore to make the most of this rich cultural diversity in New Zealand, the ability for young people to communicate effectively and work well with classmates from China and other cultural backgrounds is essential.

Internationally, many countries look to China for diplomatic relations and trade, and Chinese-speaking communities are found all over the world. China wants the number of foreigners learning Chinese to grow and has implemented several initiatives worldwide to develop CFL (Scrimgeour \& Wilson, 2009; Tian \& Lowe, 2014). Successful cross-cultural relationships rely on intercultural 
competence and ICC. Linguistic proficiency without intercultural understanding is not enough for successful understanding. Liddicoat (2008) points out that native speakers can often be quite accepting of grammatical inaccuracies, but "cultural mismatch often creates significant problems for communication and for social relationships" (Liddicoat, 2008, p. 278).

To a non-Asian background learner of Chinese, Chinese culture is arguably more different and difficult to come to grips with than other European cultures. Several studies have documented how a lack of intercultural competence and ICC has negatively impacted on CFL learners in China and Chinese native speakers in foreign countries. Yang (2009) and Tian and Lowe (2014) have reported on international students in China initially lacking knowledge to help encounter 'otherness' in Chinese culture and in Chinese perceptions of their own culture. As a result, students feel alienated, are slow to make progress in language learning, and find it difficult to participate in Chinese society due to differences and lack of understanding of cultural values.

Other studies have focused on the difficulties experienced by Chinese native teachers lacking in ICC training when they arrive in a foreign country. In a study examining Chinese language teachers' expectations and perceptions of American students' behaviour, Zhou and Li (2014) found that native Chinese CFL teachers lacking a knowledge base in the social and cultural contexts of the Western classroom also experienced classroom management difficulties. However, once the CFL teachers received support from local teachers and began to adopt culturally appropriate strategies, there was a reduction in discipline problems (Zhou \& Li, 2014). These studies highlight the point made in the literature that intercultural competence is not learned just from exposure to the target culture (Liddicoat, 2011; Lo Bianco et al, 1999). It is a process which needs to be deliberately taught, perhaps even more so when the target culture is perceived as 'exotic' (Tian \& Lowe, 2014).

Although it is not at the forefront of issues in CFL research, the importance of teaching culture in the CFL classroom has received some attention from CFL teachers and researchers (Chen, 2008; Danison, 2013; Diaz, 2013; Orton, 2011; Scrimgeour \& Wilson, 2009; Tsung \& Cruickshank, 2011; Wong, 2008; Xing, 2006; Yu, 2008). There is some agreement that some features of the 
intercultural model make it a desirable approach for teaching culture in CFL programmes (Diaz, 2013). However, the interpretation of ICLT theory and practice in the CFL classroom is seen as complex (Wong, 2008; Orton, 2011) and considered a new area for research. The current theorising of culture and approaches to culture emphasises the need to reassess how this is done in CFL. Proposed models are vague and lack the reflexive and critical comparing of the target culture and of their own culture, which is key to ICLT.

In reviewing the International Curriculum for Chinese Language Education (ICCLE), from the Office of Chinese Language Council International, Scrimgeour and Wilson (2009) praise the initiative to organise and describe objectives and content for a standardised Chinese language curriculum around the world. However, in the curriculum, culture is described as an optional component and is separated from language learning. Scrimgeour and Wilson (2009) criticise that although the curriculum includes a cultural awareness component, it needs to readdress how language could be embedded in a dynamic cultural context. Other researchers have echoed this need to readdress the "welding of language and culture" (Wong, 2008, p. 3) in the CFL classroom.

Chen (2008) and Wong (2008) both agree that CFL teaching requires more attention to be given to the teaching of culture. Chen (2008) acknowledges that the most commonly used model of teaching culture in CFL is the additive model, whereby explicit factual knowledge about Chinese culture is taught alongside a language programme. Although the positive aspects of this model are mentioned, Chen (2008) discusses the need to move beyond an ethnocentric view of culture in the CFL classroom and to focus on intercultural communication and intercultural understanding. He draws on existing models of teaching culture in order to develop a more dynamic approach. A new model which promotes "learning to know, learning to do and learning to interact" (Chen, 2008, p. 87) is proposed. Chen (2008) believes that CFL teachers need to tap into the learners' cultural creativity to develop intercultural communication and intercultural understanding. He describes this process as moving from "known to unknown, from existing experience to new knowledge, from new knowledge to new understanding" (Chen, 2008, p. 87). Whilst this model has some common points with ICLT, namely that understanding culture is a dynamic 
process and involves interaction and an experiential element, details of the model are vague, and the reader is left unsure exactly how one can move further with the proposal. There appears to have been no further follow-up of this proposal.

Wong (2008, p. 1) proposes the " $4 \mathrm{P}^{\prime}$ 's of cultural pedagogy" as a new model for teaching culture in CFL. This model aims to place equal importance on language and culture. The 4P's include the following: 1 ) the notion of plurality that Chinese culture is diverse and found well beyond China, 2) progressivity that Chinese culture is dynamic and continually evolving, 3) positionality - that the social position of students and teachers plays a role in understanding culture, and 4) performativity - that culture needs to be performed in order to develop a deeper understanding of it. Wong's model includes some important points which have been neglected in CFL teaching, in particular the consideration of Chinese culture outside of China. In relation to ICLT, the 4P's of culture model shares common ground. Within the 4P's model, culture is viewed as dynamic and inclusive of social practice, like ICLT. However, as in the Chen (2008) proposal, in the 4P's model, there is no concrete mention of comparing, exploring and mediating between cultures, which is at the heart of developing ICC. Further discussion of the 4P's model for cultural pedagogy has not appeared in CFL journals.

In contrast to the theoretical proposals of Chen (2008) and Wong (2008), Xing (2006) provides more practical advice about how to teach culture in her book Teaching and learning Chinese as a foreign language: A pedagogical grammar. She touches on 'intercultural communication', citing the work of Byram (1997) and Kramsch (1993). However, her recommendations for teaching culture in CFL are based on language proficiency as the primary goal of teaching and learning a foreign language. Xing (2006, p. 241) suggests that culture as a concept "should be introduced and explained to students whenever it enhances language learning and advances language proficiency." Her rationale for this lies in the belief that a CFL speaker with high language proficiency is most likely to have a thorough knowledge of the Chinese culture, as linguistic and cultural competence increase alongside each other. This implies that 
assimilating native speaker linguistic and behavioural competence is the ultimate goal for a CFL learner.

Furthermore, Xing (2006) lists numerous appropriate topics which might be considered for teaching culture. In doing so, Xing (2006) seems to have understood intercultural communication to involve culture as the acquisition metaphor (Sfard, 1998), factual or static knowledge. She presents five categories tradition, attitude, ritual, belief, and social behaviour and attributes different subtopics under each category; for example under tradition: personal names, festivity, medicine (for further detail see Xing, 2006, pp. 242-243). The list of categories and subtopics is useful for teachers who are unsure where to begin in teaching culture. However, there is no mention of a conscious, comparative, reflexive, critical, and ongoing process whereby learners examine their own prior experiences of their own culture in order to mediate an intercultural "meeting place" for experiencing and accepting Chinese culture, the process designed to develop ICC.

With regards to developing a languaculture approach (exploration of culture through language (Liddicoat \& Scarino, 2013)), Diaz (2013) discovered two differing attitudes from Chinese native speaker lecturers to including culture and the intercultural in a case study of two courses in an Australian university Chinese programme. As part of her case study, Diaz undertook participatory action research (PAR). PAR is a collaborative and participatory process whereby the researcher works as a co-worker with teaching participants doing research to examine a "practical problem and its actual improvement" (Diaz, 2013, p. 64).

Data from Diaz's study show that the Chinese language programme took an "ad hoc" approach to the inclusion of culture and that linguistic proficiency was the main goal in language teaching (Diaz, 2013, p. 94). The course aim was "to provide students with a basic knowledge of Chinese language and culture through the study of prepared or selected texts structured around set topics" (Diaz, 2013, p. 95). However, the textbook included no cultural knowledge, and the teacher in charge of the course believed that the inclusion of cultural knowledge depended on the individual teacher. PAR interventions aiming to introduce an intercultural dimension to the course were received well with students, but the participant teacher was resistant and believed that time spent 
discussing intercultural explorations was wasted and should be spent on developing linguistic competence.

In contrast, Diaz (2013) worked with a different teacher of a compulsory course on Chinese culture taught in English. Both the lecturer and the students of the course were extremely positive about the PAR interventions. Data showed that the development of the intercultural dimension led to quality reflections regarding the interplay of language and culture and a deeper understanding of interactions between native and non-native speakers of Chinese. The lecturer found the training process in which she learnt about the languaculture approach a "rare opportunity for her professional development and personal growth" and declared that she was now "desperate, passionate about the area" (Diaz, 2013, p. 110). The successes and lack thereof in attempting to work with CFL lecturers to develop the intercultural dimension in tertiary language programme highlights the importance and need for on-going professional development in this area for language teachers.

This literature review has shown that although developing ICC through ICLT is the goal for foreign language education in curriculum documents worldwide, ICLT is far from the pedagogical norm in foreign language classrooms in New Zealand and elsewhere. The specific field of CFL appears relatively untouched by recent publications and dissemination of research in ICLT and on the important role of ICC in developing successful intercultural relationships in our "super-diverse and globalised"(Byram, 2014, p. 222) world. Research (e.g. Byram, 2013, 2014; Diaz, 2013; Kohler, 2015) suggests that the major obstacle in developing ICLT in foreign language education has been in reaching teachers with new ideas. In addition, Byram $(2013,2014)$ and Liddicoat (2013) stress the need for more classroom-based studies, which make the marrying of theory and practice of ICLT more accessible to classroom teachers. For this reason, Byram stresses the need for more teacher-led research in the field.

\section{Rationale for the research and research questions}

The gap in the literature of ICLT in practice and particularly in relation to developing ICC in CFL presents me, as both a CFL teacher and researcher, with 
the opportunity to examine how ICLT can be implemented in the CFL classroom. In view of the fact that CFL teachers are not widely aware of ICLT theory and do not widely practise ICLT, it seems that a logical place to begin exploring the opportunities for developing ICC is to examine naturally arising opportunities ${ }^{4}$ of ICLT in a CFL classroom and if/how they are acted upon. Once naturally arising opportunities have been identified, they can be used as a platform for a more conscious development of ICC in the classroom.

As an important aside, it should be noted that research in all areas of CFL has heavily focused on one population, namely beginner American university students (Everson, 2008; Jiang \& Cohen, 2012). The numbers of primary and secondary students who are learning CFL are rapidly increasing internationally, and therefore research into linguistic and cultural issues of CFL must include this population. ICLT research has also been predominantly focused on teacher understanding and practices (Conway \& Richards, 2014; East, 2012; Kohler, 2015; Oranje, 2013, 2014; Sercu, 2006). Therefore, this thesis presents case study research in a new environment - a CFL classroom at secondary school level, which includes data collected from the teacher and student perspectives. My research project is guided by the following questions:

1. What naturally arising opportunities are available for the development of intercultural competency and ICC through ICLT in a Year 11 CFL class at a New Zealand high school?

2. What cultural and intercultural views and beliefs about teaching and learning CFL emerge from the participants?

3. How does the picture which emerges from the data of this CFL classroom fit into the overall picture of ICLT in practice in the literature so far?

\section{METHODOLOGY}

Conducting a case study allows me to collect qualitative data in a way that creates a rich and thick description of lived reality in a classroom (Duff, 2012;

\footnotetext{
${ }^{4}$ As the teacher is unaware of ICLT, 'naturally arising opportunities' refer to aspects of ICLT in the classroom which occur without the teacher consciously using ICLT theory or the iCLT framework of principles to develop intercultural competency.
} 
Kohler, 2015). My study seeks to provide FL teachers and researchers with an accessible, concrete, and personal picture (Duff, 2012) of opportunities for marrying the practice and theory of ICLT. A case study approach allows for flexibility and sensitivity as data collection can fit around the schedules of the teacher and the students. This is essential when investigating a busy classroom. The case study approach also enables exploration of the views and experiences of both the teacher and students in the class. Researching both the teacher and student viewpoints and experiences of teaching and learning about Chinese culture permits me to examine different perspectives and to compare links between similarities and differences from the participants (Diaz, 2013; Kohler 2015).

\section{Setting and participants}

McLean Girls' High School ${ }^{5}$ is a large inner city single gender state school in a major city in New Zealand. It is a decile 10 school. ${ }^{6}$ Many students come from a wide variety of cultural backgrounds, though the majority are New Zealand European. Foreign language study is well supported and encouraged at the school. Mandarin has been taught for almost 30 years.

I approached the CFL teacher and the principal of McLean Girls' High School in 2014 in order to check whether this study would be feasible. Once the study had received the principal's approval and ethics approval I visited the class and invited interested students to take part in the study. The following describes the case study participants.

The head Mandarin language teacher Catherine ${ }^{7}$ has lived in New Zealand for twenty years and has been teaching Mandarin for fifteen years. She is a native Mandarin speaker with native-like proficiency in English, and she majored in French for four years at university in China. Catherine is a well-respected

\footnotetext{
5 The school name has been changed.

${ }^{6}$ A decile ten school indicates that the majority of students attending the school come from a high socio-economic background. All New Zealand schools are assigned a decile level from one to ten (ten being the highest) according to economic and social factors of the students attending the school.

7 The pseudonym was chosen by the teacher.
} 
member of the Mandarin language teaching community and has participated in Chinese assessment design at a national level.

Three students signed up to participate in the study. All three students who participated in this study are in their third year of Mandarin study at high school. During the time of this study the participants were preparing for NCEA ${ }^{8}$ Level One internal and external assessments. Student One, Samantha ${ }^{9}$, is Korean. She speaks Korean at home and has lived in New Zealand for six years. Observationally, her English proficiency is native-like. Student Two, Lucy, is a New Zealander. Lucy speaks English at home and has taken short courses in French and Latin. Student Three, Kelly, is American but has lived in New Zealand for ten years. She has taken a short course in French and speaks English at home. Kelly did not participate in the full study. She was interviewed once at the beginning of the data collection period before she moved back to the United States with her family. All three students are considered to be high achieving students in all or most curriculum areas in the school.

In order to accurately interpret the findings of this study, it is imperative to first reflexively consider my own relationship with the participants in the study as well as my role in the study. I am also a teacher of Mandarin, French, and German at the same school. The participant teacher is my friend and colleague, and we have taught at the school for twelve years together. I taught Lucy and Kelly in their first year of learning Mandarin at high school. Since teaching these students, I have remained in friendly contact. Although I did not teach Samantha, we both knew of each other from being part of the same school community.

Any relationship or lack thereof always influences the behaviour of those involved in the research. While my familiarity with the participants will have altered their behaviour in the study, my existing relationships with the students and the teacher are positive for the study. As the participants already knew me relatively well, I was able to fit into the classroom environment in a natural and

${ }^{8}$ NCEA (National Certificate of Educational Achievement) is the national set of assessments which students attending New Zealand high schools sit in Years 1113 (the third, fourth and fifth years of high school). NCEA level 1 Chinese requires a low intermediate language proficiency, roughly the equivalent level to A2 in the European Common Framework.

${ }^{9}$ All student names have been changed. 
relaxed manner. Participants were enthusiastic about taking part in the study and appeared comfortable sharing opinions and ideas with me as a researcher.

\section{Data collection}

Qualitative data was collected over fifteen weeks (over two school terms). The first five weeks were spent observing one class per week, and enabling the students and teacher to get used to my presence. Formal data collection began at the beginning of Term 3, 2015 and five hours and forty-one minutes of audio and video recorded data were collected over the course of ten weeks (explained further below). Data collecting methods included classroom observations, formal, informal and semi-formal interviews, stimulated recall based on openended prompts from audio footage of class, field notes and a final written reflection from the students. These methods were intended to be non-disruptive to the class and to be used to study the teaching and learning of Chinese in an everyday setting.

So as to incorporate depth in the observations, I was a participant observer, with various levels of engagement assisting the teacher, in and out of the classroom. During Term 3, on average, one lesson every two weeks for one hour each time was video recorded, and I sat in on this lesson. When the teacher was too busy with the daily pressures of school life, I did not collect classroom data. In addition to the video recording, the student participants had a digital audio recorder on their desks to enable me to more precisely transcribe their spoken contributions during class.

Emergent issues which arose from the observations such as cultural jokes, comments with cultural stereotyping, and class cultural activities were used as video and audio recorded stimulated recall. Stimulated recall is a data collection tool which aims to explore the participant's thought processes or strategies. Participants are shown a visual or audio prompt from classroom observation footage and consequently invited to comment on their thought processes and motivations during the time of the footage (Mackey \& Gass, 2005). Stimulated recall sessions with students were carried out between three to seven days after the observation in the alternate weeks when I did not observe the class. These discussions were conducted as informal and semi-formal 
interviews (Mackey \& Gass, 2005). Discussions took place during lunchtimes or convenient meeting times throughout the data collection period in small meeting rooms in the languages department of the school. Both Samantha and Lucy chose to do the final interview (Appendix 1) as a written reflection. Kelly was interviewed once during the study before leaving New Zealand. She was no longer attending the school once the recorded classroom observations had begun.

Additionally, I chose not to use stimulated recall with the teacher in order to fit in with her busy teaching load. Instead, the teacher participated in one formal interview at the end of the data collection period, which also fit her expectations of her commitment in the study. I provided her the questions (Appendix 2) for the interview a week in advance in order to give her more time to consider her views in depth and to maximise the data obtained from the short period of time available for interview.

All interviews were audio recorded, and relevant excerpts were transcribed. The transcripts were checked with the participants for accuracy and used as another form of stimulated recall.

\section{Data analysis}

Audio and video recorded data from the observations, stimulated recall and interviews were transcribed and coded for qualitative analysis. A content analysis approach was used to analyse the data in order to undertake a "holistic and comprehensive" (Nguyen, 2014, p. 70) analysis of a social and educational context. NVivo 10 software was used to store the data and manage the coding process. Following the grounded theory approach as described in Charmaz (2014), Friedman (2013), and Nguyen (2014) in which codes emerge naturally from the data, the data were initially coded, resulting in Child nodes (Table 1). Child nodes were assigned in 'speaker turns' (Koiso, Horiuchi, Tutiya, Ichikawa \& Den, 1998) or utterances between silences to relevant topics to the study.

Once the initial codes were established and reviewed, I examined the data for patterns and connections in order to develop a structure of categories (Parent nodes, Table 1) and subcategories (Child nodes). As clearer pictures in the data emerged, the categories were grouped into themes (Grandparent nodes, 
Table 1). The coding process drew on and was shaped by the literature and my own professional and academic knowledge of ICLT.

The final themes essentially aligned with Newton et al's (2010) framework of six principles of iCLT. Newton's new look revised principles (Newton, 2014), the work of Kramsch (1993) and Liddicoat and Scarino (2013) influenced my interpretation of the themes in relation to the iCLT principles. In addition to the six themes based around the Newton principles, one other theme clearly emerged from the data. This theme examines the potential opportunities that might be able to incorporate an ICLT approach in the classroom. This theme contained 99 references - the second highest number of references in the coding schema.

Table 1

\begin{tabular}{|c|c|c|}
\hline $\begin{array}{l}\text { Themes } \\
\text { (Grandparent nodes) }\end{array}$ & $\begin{array}{l}\text { Categories } \\
\text { (Parent nodes) }\end{array}$ & $\begin{array}{l}\text { Subcategories } \\
\text { (Child nodes) }\end{array}$ \\
\hline $\begin{array}{l}\text { iCLT Principle 1: iCLT } \\
\text { integrates language and culture } \\
\text { from the beginning }\end{array}$ & - Language & $\begin{array}{l}\text { - } \text { Cultural content } \\
\text { - } \text { Cultural stereotypes } \\
\text { - } \text { Cultural empathy } \\
\text { - } \text { misunderstandings } \\
\text { - } \text { knowledge } \\
\text { - } \text { cultural focus } \\
\text { secondary to language } \\
\text { learning } \\
\text { - Cultural humour } \\
\text { Cultural learning to } \\
\text { avoid } \\
\text { misunderstandings } \\
\text { - Student interest in } \\
\text { cultural content } \\
\text { - Teacher discussion of } \\
\text { culture with researcher } \\
\text { - Chinese language } \\
\text { Chinese used for } \\
\text { classroom management } \\
\text { Chinese used in a } \\
\text { uniquely Chinese way } \\
\text { English used in a } \\
\text { Chinese way } \\
\text { Explicit linguistic } \\
\text { comparisons } \\
\text { - Imitation } \\
\text { - Language and culture } \\
\text { Language as the main } \\
\text { focus }\end{array}$ \\
\hline $\begin{array}{l}\text { iCLT Principle 1: iCLT } \\
\text { integrates language and culture } \\
\text { from the beginning }\end{array}$ & - Culture & $\begin{array}{ll}\text { - } & \text { Cultural content } \\
\text { - } & \text { Cultural stereotypes } \\
\text { - } & \text { Cultural empathy } 34 \\
\text { - } & \text { Cultural } \\
& \text { misunderstandings }\end{array}$ \\
\hline
\end{tabular}




\begin{tabular}{|c|c|c|}
\hline $\begin{array}{l}\text { iCLT Principle } 2 \text { : iCLT engages } \\
\text { learners in genuine social } \\
\text { interaction }\end{array}$ & $\begin{array}{ll}\text { - } & \text { Social } \\
& \text { interaction }\end{array}$ & $\begin{array}{l}\text { - Interaction practice } \\
\text { - Social goals in the } \\
\text { classroom }\end{array}$ \\
\hline $\begin{array}{l}\text { iCLT Principle 3: iCLT } \\
\text { encourages and develops an } \\
\text { exploratory and reflective } \\
\text { approach to culture and } \\
\text { culture-in-language }\end{array}$ & $\begin{array}{ll} & \text { Reflections } \\
\text { - } & \text { Perceptions } \\
& \text { and opinions }\end{array}$ & $\begin{array}{ll}- & \text { Student reflections } \\
\text { - } & \text { Teacher reflections } \\
\text { - } & \text { Student opinion of } \\
\text { classroom experiences } \\
\text { - } & \begin{array}{l}\text { Student perceptions of } \\
\text { culture }\end{array}\end{array}$ \\
\hline $\begin{array}{l}\text { iCLT Principle 4: iCLT fosters } \\
\text { explicit comparisons between } \\
\text { languages and cultures }\end{array}$ & $\begin{array}{l}\text { - Comparisons } \\
\text { - Connections }\end{array}$ & $\begin{array}{ll}- & \text { Cultural comparisons } \\
\text { - } & \text { Linguistic comparisons } \\
\text { - Learning beyond the } \\
\text { classroom } \\
\text { - } \\
\quad \text { Experiential element of } \\
\text { language learning }\end{array}$ \\
\hline $\begin{array}{l}\text { iCLT Principle 5: iCLT } \\
\text { acknowledges and responds to } \\
\text { diverse learners and learning } \\
\text { contexts }\end{array}$ & $\begin{array}{ll} & \text { Diversity } \\
\text { - } & \text { Personal } \\
& \text { experiences }\end{array}$ & $\begin{array}{ll}- & \text { Ethnic diversity } \\
\text { - } & \text { Ethnicity of } \\
\text { participants } \\
\text { - } & \text { Teacher sharing of } \\
& \text { experiences } \\
\text { - } & \text { Teacher training }\end{array}$ \\
\hline $\begin{array}{l}\text { iCLT Principle 6: iCLT } \\
\text { emphasizes intercultural } \\
\text { communicative competence } \\
\text { rather than native-speaker } \\
\text { competence }\end{array}$ & $\begin{array}{l}\text { - } \begin{array}{l}\text { Student use of } \\
\text { language }\end{array} \\
\text { - } \begin{array}{l}\text { Student beliefs } \\
\text { about language } \\
\text { use }\end{array}\end{array}$ & $\begin{array}{ll}\text { - } & \text { Student rule based } \\
\text { - } & \text { Spproach to language } \\
\text { language freely } \\
\text { - } & \text { Cultural } \\
\text { misunderstandings } \\
\text { - } & \text { Student perceptions of } \\
\text { culture }\end{array}$ \\
\hline $\begin{array}{l}\text { Potential opportunities for } \\
\text { integrating ICLT }\end{array}$ & $\begin{array}{l}\text { - } \text { ICLT in action } \\
\text { - Areas which } \\
\text { could benefit } \\
\text { from ICLT }\end{array}$ & $\begin{array}{ll}\text { - } & \text { Recognition of culture } \\
& \text { and language as } \\
& \text { connected } \\
\text { - } & \text { Cultural empathy } \\
\text { - } & \text { Student reflections } \\
\text { - } & \text { Cultural stereotypes } \\
\text { - } & \text { No uptake on cultural } \\
\text { - } & \text { activity } \\
& \text { Cultural } \\
& \text { misunderstandings }\end{array}$ \\
\hline
\end{tabular}


Discourse from the themes was transcribed (Appendix 3) in intonation units (Tannen, Kendall, Gordon, 2007) and analysed, using an interactional sociolinguistic (IS) approach to discourse analysis. The IS approach "explicitly recognises the wider sociocultural context interacting on interactions" (Stubbe, Lane, Hilder, Vine, Vine, Marra, Holmes, \& Weatherall, 2003, p. 358). As ICLT involves negotiating culture through reflection and comparison of one's own culture, the IS approach allows the analysis "to take explicit account of the unstated assumptions and background knowledge the participants in an interaction bring to bear as part of the interpretive process" (Stubbe et al, 2003, p. 362).

\section{FINDINGS}

Newton et al's (2010) framework of six principles for iCLT, designed specifically to support the teaching of intercultural communicative competence in the New Zealand language classes, provides the theoretical framework through which I interpret the findings in the analysis. Newton's 2014 version of the iCLT principles and other publications in the field (Conway \& Richards, 2014; Kramsch, 1993; Liddicoat \& Scarino, 2013, Newton, 2014 \& Sercu, 2006) have further informed the interpretation of the applied Newton principles. In this section naturally occurring incidents of each iCLT principle in the data will be individually discussed alongside teacher and student views of teaching and learning culture. ${ }^{10}$ Potential opportunities for incorporating ICLT from the data will be integrated into the findings for each principle before the whole system is reviewed in relation to the research questions.

\section{iCLT Principle 1: ICLT integrates language and culture from the beginning}

Principle 1 recognises the interconnection between language and culture, emphasising that all languages carry culturally "embedded understandings" (Liddicoat, 2008, p. 280) and therefore cannot be taught as separate entities

10 Only the dialogue of consenting participants has been transcribed, therefore excerpts do not always contain the full detail of the conversations. 
(Byram, 2014, Newton et al 2010). The interconnection between language and culture reinforces the view of culture as a social practice which is complex and dynamic (Liddicoat \& Scarino, 2013), not just a static set of facts to be learnt separately from the language.

Excerpt 1 shows how Catherine's actions and use of language in the classroom demonstrate the inextricable link and interconnection between language and culture. Her language and actions model how a Chinese speaker might use and adapt language in varying situations depending on the level of formality and the tone the speaker wishes to convey.

(1) Catherine is walking around the classroom organising students to make signs in Chinese characters, pinyin, and English to label different areas around the school as part of the international languages week celebration.

(00:00:04)

$\begin{array}{llrl} & & \text { Pinyin } & \text { Gloss } \\ 1 \text { Catherine: } & \text { go go go! . . } & & \\ \text { ((Catherine walks around giving things like glue sticks to the students)) } \\ 2 & \text { 好吧? } & \text { hao ba } & \text { 'okay?' } \\ 3 & \text { 好吧? } & \text { hao ba } & \text { 'okay?' } \\ 4 & \text { glue stick 好吧? } & & \\ 5 & \text { 去吧! } & q u b a & \text { 'go!' }\end{array}$

((addressing two students)):

6 来来来! lai lai lai 'come

7 等一下! deng yi xia 'wait a bit!'

((one student gives work to Catherine to check for accuracy))

8 shei '谁? 'who?'

9 我看一下! wo kan yi xia 'let me have a

10 很漂亮 hen PIAO LIANG 'so beautiful!'

11 都对了! dou duile 'all correct!'

12 十一个好? Shiyige hao? 'there are 11 of

$13 \quad$ wow so many 楼梯! louti 'stairs' them right?'

((louti here refers to the students writing out labels with Chinese characters for stairs))

(00:00:44)

In this excerpt when encouraging or praising students with repetitive formulaic phrases (好吧? 好吧? lines $2-4,6$ ), Catherine uses a natural informal style of spoken Chinese as would be heard in the home, on the street in China, or in 
Chinese speaking communities. This is not the formal style of Chinese presented in a textbook for foreigners with typical phrases of a single utterance such as “请进 。。请坐' - please come in please sit (Chang, Mackerras \& Yu, 1995, pp. 7-8).

In lines $2,3,4$, and 6 , there is rapid excited repetition of short formulaic phrases such as 'hao ba (okay)' and 'lai (come)'. Catherine uses these phrases as part of her classroom management to keep the momentum and interest of the class activity in a friendly, informal, and encouraging way. The repetition softens the command form 'lai (come)' to encourage the students in their activities. Line 1 indicates that Catherine has carried this trait into her English speech as she says 'go go go' to speed up the students. Catherine uses the mitigating suffix ' $y i$ xia (for a bit)' (lines 7,9,) in her speech with students. Once again this suffix softens the tone of the command 'deng (wait)' to 'deng yi xia (wait for a while)' (line 7) providing the students with a natural example of how speech is mitigated.

As she regularly performs culture in the classroom, Catherine's cultural identity as a Chinese person living in New Zealand is anchored in the way she uses language and interacts with the students (Halliday, 1990). This finding is similar to the findings in Danison's (2013) study of the treatment of culture in a university CFL classroom. Danison (2013) found that although the teacher did not explicitly include any cultural dimension, the native speaker teacher played a key role in the students' conceptualisation of Chinese culture. As a native speaker who is using Chinese in a conversational and at times informal ways, Catherine is incorporating iCLT Principle 1 of language and culture being integrated from the beginning. For many students who have few experiences of China or Chinese culture, she embodies China and Chinese culture. Lucy reflects that having a native speaker teacher is an invaluable source of cultural input: ' $I$ think I learn more about Chinese culture through Ms Su.' (Written reflection, September, 2015).

In addition to using language in cultural context (for example how Catherine would use Chinese in China), Catherine mixes Chinese and English regularly in her speech in the CFL classroom in New Zealand, demonstrating how language and culture work together as complex and dynamic social practices 
(Liddicoat \& Scarino, 2013). Catherine was born and raised in China but has now lived in New Zealand for 20 years. Her use of Chinese and English has evolved according to her personal experience of where she lives and works. In the phrase 'glue stick hao ba' (Excerpt 1, line 4) Catherine surrounds the English word with Chinese syntax and uses translanguaging as a communicative strategy (Gumperz, 2005) to ensure the student has understood the classroom instruction to stick the labels on with glue. Although translanguaging in this instance is used to convey pragmatic meaning, her regular switching between languages is both noticed and imitated by students in the class normalising such linguistic behaviour in the Chinese in New Zealand context.

An example of students using this strategy is when Samantha describes a holiday in Christchurch as “很 cold (very cold), ' (classroom observation, August, 2015). In modelling translanguaging as a communicative strategy in class, Catherine is showing students one way in which students can operate smoothly between languages and cultures. Translanguaging provides students with one tool to begin to find and explore the intercultural 'third space' (Kramsch, 1993).

Furthermore, during the final interview (Excerpt 1.2) Catherine discusses her understanding of how language and culture are integrated and thus shows her interpretation of the first iCLT principle.

(1.2) Catherine and I have been discussing what and how she teaches culture in her Chinese classes.

(00:05:59)

$1 \mathrm{Me}:$

2 Catherine:

3

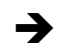

4

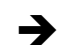

6

this vocabulary))

(00:06:15) so you teach people through discussions in the class? yeah, even when we are teaching vocabulary we are teaching culture, like teaching “你和您”11 what is the difference? what is the cultural knowledge they should know? ((about

In mentioning the two different forms of 'you', formal and informal, (lines 3-6)

Catherine shows she understands that vocabulary cannot be fully understood

11 “你和您' ni he nin - the informal and formal forms of 'you'. 
without understanding the cultural context of particular words. She mentions that it is important for her to teach students about 'the difference' between the two words for 'you' (the formal and informal forms) and what 'cultural knowledge students require to use this vocabulary (lines 5 and 6). This belief is evident in her teaching practice at times. Excerpt 1.3 shows Catherine discussing the cultural significance of specific vocabulary with students in class.

(1.3) Catherine and some students are discussing the different Chinese words which are possible for bathrooms as the students are labelling the school in Chinese (and other languages) as part of international languages week celebrations.

$(00: 01: 08)$

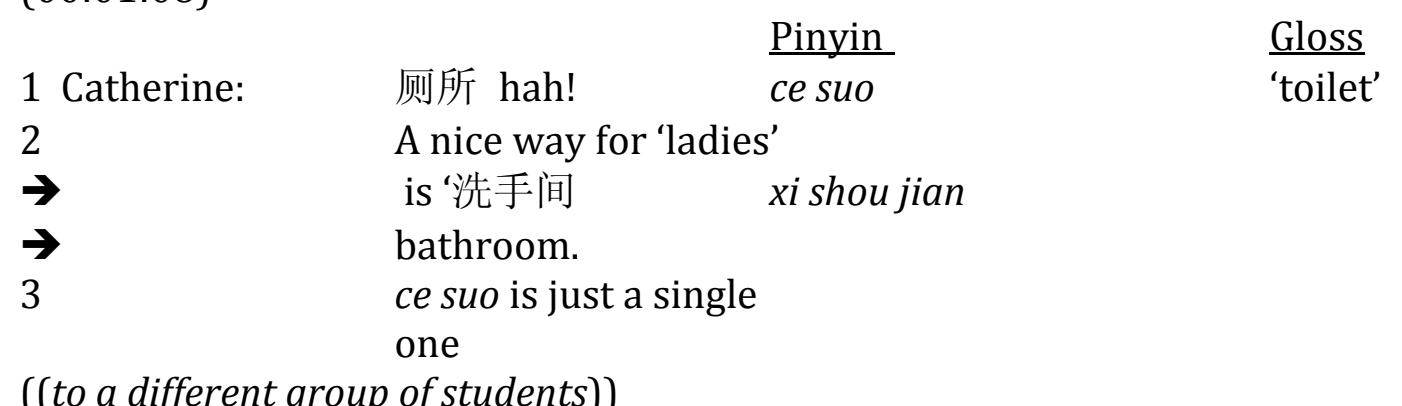
$\begin{array}{lll}4 & \text { 你去一下! } & \text { 'you go for yi xia } \\ & & \text { a bit!' }\end{array}$ (00:01:36)

Catherine sees and comments on one student's label 'ce suo (toilet)' and says 'hah!'(Excerpt 1.3, line 1). She notices that although the literal meaning of 'ce suo' is correct, it is not appropriate to label the bathrooms in the school with just 'ce suo'. She says to the students 'a nice way for 'ladies' is 'xi shou jian' bathroom' (line 2). Though not explicit, in referring to the more polite English terms 'ladies' and 'bathroom', Catherine implies that 'xi shou jian' (literally 'wash hands room') is the appropriate word for the context. This discourse between student and teacher provides an example of how Catherine teaches her students that understanding requires comprehension of cultural context as much as language (Hymes, 1972, Kramsch, 1993).

Although there are naturally occurring instances of language and culture being taught, learnt and experienced as interconnected and dynamic systems, the data reveal that classroom practices and students seem to view language and language proficiency to be more important in the CFL classroom. Students 
Samantha, Lucy, and Kelly predominantly seem to view culture as static knowledge and something to do once the serious work has been completed.

Throughout the data Samantha appears to view language proficiency and successful marks as the most important goals of her studies. Excerpt 1.4 is part of a stimulated recall session, and Samantha discusses what she was thinking during class whilst practising with her classmate for an up-coming speaking test.

(1.4) Samantha has just heard part of a practice dialogue between herself and a friend. The tone of the dialogue was animated and touched on cultural content with the students discussing the food which Samantha's friend ate on her holiday in France.

$1 \mathrm{Me}:$

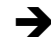

2 Samantha:

$\rightarrow$

3

4 Me:

$\rightarrow$

5 Samantha:

(00:03:11)
So you and ${ }^{* * *}$ are having a bit of a chat about your holidays and I was wondering what you were thinking about here? ah I was just trying to continue the conversation as fluently as possible because it was just practice for the interaction so I think I was just trying to make up any or think of any good words that could be matched in that sentence, ya ok so it was about putting together language [just to help you make the conversation flow]. [YAH, YAH]

Samantha reflects that during the dialogue she was trying to converse 'as fluently as possible' (line 2) and 'make up or think of ... good words' (line 3) to be matched in a sentence. She views the dialogue as just practice for the interaction' (line 2). In line 4, I check that I have understood that Samantha was mainly focused on language and she emphatically replies 'yah, yah' (line 5). Samantha's view on how to successfully perform the dialogue appears to be measured in linguistic terms: fluency, vocabulary and sentence structure. For her, the point of the dialogue is to practise for an assessment. Samantha's reflection on the importance of language proficiency in learning Chinese, especially in relation to assessment, is apparent throughout the data. In response to being asked if she would like more class time to discuss cultural aspects she replies 'if it is to do with class work it will be better to have more time to revise more.' (Written reflection, September, 2015).

Lucy also appears to perceive language proficiency as the most important outcome of the course. During one class Lucy prepares for her interaction 
assessment by writing down possible sentences she might say. As she completes one sentence she says to her friend:

I have a really good sentence, you are going to be really impressed it is:

"although catching a plane is really expensive it only takes one hour" maybe one and a half hours. It's deep stuff! (Classroom observation, August, 2015)

After playing Lucy the above quotation as stimulated recall, Lucy mentions why she is pleased about her sentence in Excerpt 1.5.

1Me:

2 Lucy:

3

4

5

(00:01:32)
Tell me about your good sentence ah because Ms Su has these sentence structures she likes, like 'although' 'danshi' although you wouldn't say that in English. And she really likes it when we use them so I thought she would be impressed that I'd used one.

Lucy explains that she believes her sentence is good because it uses a sentence structure which the teacher likes (line 2). She recognises that if she uses this structure in her assessment she might impress the teacher (line 5). Once again the mention of sentence structure, in relation to achieving success in the language classroom and assessments, implies that language proficiency is the main focus in the classroom. Lucy attributes this focus on linguistic proficiency as coming from her teacher in saying 'Ms Su has these structures she likes (line 2)' and 'she really likes it when we use them (line 5).' Both Samantha and Lucy's view, of language being the main focus in class, is reiterated by Kelly in her one interview. She remarks about the cultural content 'I don't think it is really the main focus ... you don't get a huge idea of what the actual culture is.'

In relation to Catherine's view of the integration of language and culture in the CFL classroom, interview data suggest that Catherine is supportive of the intercultural approach wherein language and culture are taught as interconnected and treated as equally important. However, in the data Catherine's views and classroom practices differ. Catherine views culture in the language classroom 'as of course very important' and sees cultural 
understanding as helping people 'to gain better communication.' (Interview, September, 2015). Her philosophy of learning about culture to 'avoid misunderstanding' is closely linked to the early thinking of intercultural theorists (Byram, 2014). Catherine appears to have noticed that the role of integrating culture in the CFL classroom is becoming more important. In her final interview she comments:

when I studied at teachers college ... 15 years ago ... cultural stuff in our group not actually that important. We were not given too much information ... about that but our recent professional development, ... conference or ... other meetings with Chinese teachers ... PD sessions in the department, we shared and focus more and more on culture. (Interview, September, 2015)

Catherine's lack of training in intercultural pedagogy provides one likely explanation as to why data from student interviews and classroom observation show culture being taught and perceived as predominantly static knowledge and secondary to developing language proficiency. Classroom observation data suggest that Catherine's teaching practices are more closely aligned with the communicative approach wherein culture is taught as factual knowledge with language acquisition as the primary focus. In Catherine's CFL classes, students participate in cultural sessions which, according to Catherine, involve watching movies, TV series, paper cutting, celebrating festivals and going to Chinese restaurants. The following excerpt is taken from a cultural session which served as both a celebration of the end of the speaking assessments and the moon cake festival.

(1.6) Students have just arrived in class and are sitting around chatting casually. Catherine arrives slightly late as she is carrying boxes of moon cakes and Chinese tea.

1 Catherine:

2

3

4

girls, girls, 我们放moon cake 好?

I just show, you know?

Moon cake is round some with yolk some with yolk free because some western people they don't eat egg,

12 我们放 moon cake 好? women fang moon cake hao - 'Shall we put the moon cake down?' 
(00:07:05) some with you know, um yeah and people would ask why you know moon cake is round, and yolk inside is round, and yolk is traditional one because both round and Chinese traditional table, dining table is round but now all the shapes can be , like old one old traditional table is round like family members all coming from all over the places and family reunion so that day lunar calendar so means everyone coming 好?

Now I serve you Chinese tea and moon cake and we continue you that ...

Here Catherine shows the students authentic moon cakes and lists facts about its round shape (line 4), different varieties - some with and some without egg yolk (line 4) and the history behind the round shape of the cake (lines 6 to 9). The information presented is purely factual and presents the moon cake festival from the culture as static knowledge perspective. In line 4, Catherine tells students that some moon cakes do not contain egg yolk 'because some western people they don't eat egg.' This generalised comment presents cultural knowledge as fact, stereotypes and polarises Western and Chinese culture implying that all Westerners do not like eating egg yolk and all Chinese people do. Cultural stereotyping will be examined in more detail in the findings for iCLT Principle 3.

For the remaining part of the lesson the students watch a Chinese film, try some moon cake and drink Chinese tea. Students express strong opinions in relation to tasting the moon cake, but experiential aspects of this cultural activity are not discussed as a class. The class finishes with Catherine showing a brief video clip providing more facts about the moon festival which some students watch attentively whilst other continue to chat or tidy up the classroom.

From the perspective of developing ICC, this particular cultural session provides the students with elements of the 'acquisition metaphor' (Sfard, 1998) with factual objective knowledge. Tasting the moon cake and watching a Chinese film presents a potential opportunity for students to engage with the 'participation metaphor' (Sfard, 1998) - contextual and personalised knowledge based on one's experience as a 'participant member of human society' (Liddicoat

13 好hao - 'ok' 
\& Scarino 2010, p. 54). However, in this particular lesson neither the teacher nor the students appear aware of this possibility.

The data suggest that naturally occurring examples of iCLT Principle 1 (integrating language and culture from the beginning), for example, teacher enactment of culture through acts and speech, and communicative strategies linking languages and cultures such as translanguaging, are modeled by the teacher and adopted by the students. However just as students seemed to have adopted some of the naturally occurring practices of Principle 1, they appear to have adopted views which are modeled on the presentation of culture as a less serious aspect of learning Chinese and of culture as static knowledge.

\section{iCLT Principle 2: iCLT engages learners in genuine social interaction}

iCLT Principle 2 recognises that learning and communication are social and interactive processes. From an intercultural perspective, social interaction provides students with opportunities to explore 'linguistic and cultural boundaries (Newton et al, 2010)' with people from varying backgrounds. In this process students may become more aware of both their own culturally constructed worlds and those of others (Liddicoat, 2008; Ministry of Education, 2007; Newton et al 2010).

Excerpt 2.1 below shows Samantha and her classmate engaging in genuine social interaction. Students are practising for an upcoming NCEA Level 1 Chinese interaction assessment ${ }^{14}$ in which they need to converse about a holiday.

14 The NCEA Level 1 interaction assessment requires students to 'Interact using spoken [target language] to communicate personal information, ideas and opinions in different situations'. Students are rewarded for 'contributing to and maintaining' the conversation with some degree of spontaneity. Genuine meaningful interaction is the aim of the assessment, not rote learnt pre-scripted role-plays. 
(2.1) Samantha and her classmate are discussing their holiday for the first time. At the beginning of the excerpt Samantha asks her friend who should initiate the conversation.

(00:02:49)

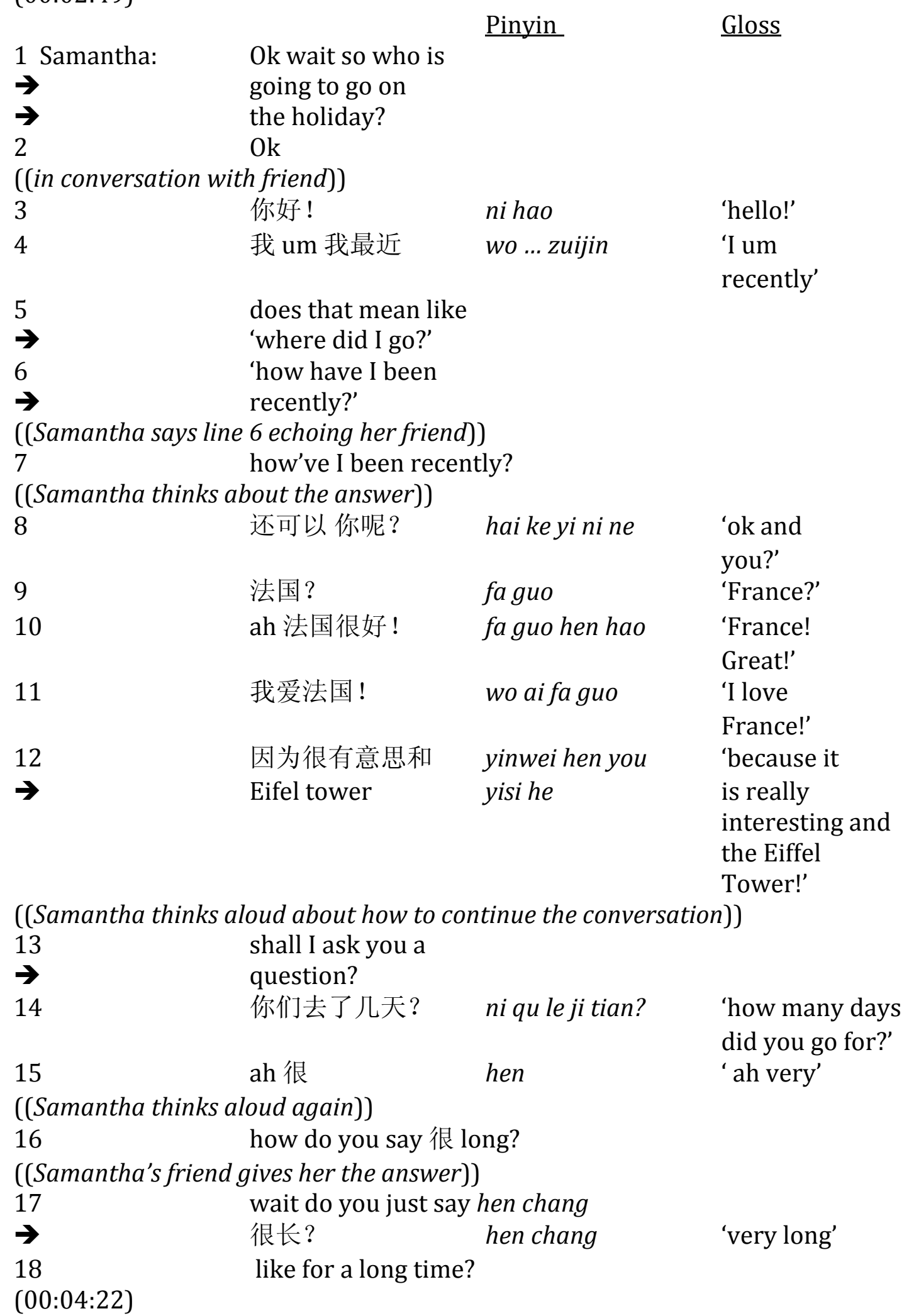


In line 1 Samantha checks in with her friend, asking who is meant to be starting the conversation and then the two students begin the conversation by greeting each other (line 3). Samantha's friend uses the expression 'ni zuijin zenme yang? (how have you been lately)'. Lines 4 and 5 indicate that Samantha misunderstands the question. Once she understands, Samantha thinks carefully about the answer (lines 6, 7), repeats the question in English and then answers that she is feeling 'ok' (line 8). Samantha's repetition of the English translation and pause in answering the question suggest that her response is genuine and not rote-learnt. Similarly, on hearing that her friend went to France during the holidays Samantha spontaneously comments 'wo ai faguo (I love France)'. Samantha subsequently adds why she loves France, because it is interesting and the Eiffel Tower (line 12), portraying her understanding of French culture as static.

Samantha talks out loud about her role in the conversation (line 13) and then asks her friend how long she stayed (line 14). In wanting to give a genuine response to her classmate's answer, Samantha would like to say 'that is very long' but she has forgotten how to say 'long' (15). Lines 16 to 18 show Samantha 'languaging' (Swain, 2006). In verbalising her thinking, 'how do you say "hen (very) long"(16), wait do you just say “hen chang (very long)", like for a long time? $(17,18)$ ', Samantha is engaging in collaborative dialogue to solve problems and build knowledge (Swain and Lapkin, 1998). Samantha's friend provides the word 'chang (long)', and the conversation carries on in the same spontaneous manner with Samantha and her friend negotiating how to use the language in context and commenting on each others' responses in a mixture of Chinese and English.

Though this class activity is essentially an exercise in speaking practice, with the focus predominantly on language forms, the speech is natural and not scripted and allows the students to engage in genuine social interaction. They negotiate meaning, respond appropriately to each other, and their interaction is spontaneous. Interestingly, as the girls run through their dialogue two more times, the spontaneity and genuine interaction remains. Although the dialogue is notably more fluent, both girls continue to collaboratively negotiate meaning and 
add new ideas to the conversation as shown in Excerpt 2.2, taken from the third run through of the interaction.

(2.2) Samantha and her classmate are discussing French food.

\begin{tabular}{|c|c|c|c|}
\hline \multirow{3}{*}{1 Samantha: } & \multirow{2}{*}{$\begin{array}{l}\text { 法国菜 hmm } \\
\text { 我也要吃法国菜和 }\end{array}$} & \multirow{3}{*}{$\begin{array}{l}\frac{\text { Pinyin }}{\text { fa guo cai }} \\
\text { wo ye yao chi } \\
\text { fa guo cai } \\
\text { he }\end{array}$} & \multirow{2}{*}{$\frac{\text { Gloss }}{\text { 'French food' }}$} \\
\hline & & & \\
\hline & 我也要吃法国菜和 & & $\begin{array}{l}\text { 'I also want to } \\
\text { eat French food } \\
\text { and' }\end{array}$ \\
\hline \multicolumn{4}{|c|}{ ((Samantha cut off by her friend $))$} \\
\hline \multicolumn{3}{|c|}{ ((sounding surprised)) } & 'I agree' \\
\hline 4 & 六块钱！ & liu kuai qian & $\begin{array}{l}\text { 'six euros!' } \\
((\text { in this context }))\end{array}$ \\
\hline
\end{tabular}

When Samantha hears that her friend went to France she makes different and more complex but still spontaneous comments to those in Excerpt 2.1. Samantha now links France with French food, once again referring to culture as static knowledge, and how she would also like to eat French food (lines 1 and 2). Samantha's friend adds that she ate French cake and that it is delicious and Samantha responds with 'wo tongyi (I agree)' (line 3). Between lines 3 and 4 her friend tells her that French cake is very expensive, six Euros and Samantha reiterates the price in line 4 . These examples show Samantha and her classmate engaged in genuine social interaction whilst practising for the NCEA interaction assessment. This evidence supports Erlam's (2015) claim that the NCEA interaction assessments in languages are a positive initiative for New Zealand language classrooms as it encourages teachers to provide more opportunities for students to engage in social interaction in the classroom and to use language meaningfully.

Based on classroom observations it appears that having students prepare for the interaction assessment in partners and allowing the students to interact more freely so they are able to negotiate meaning and learn from each other, is a new strategy for Catherine. From the engagement of the students during this class and the results achieved in the assessment, one can conclude that this strategy was successful and enjoyable for the teacher and the students. 
Prior to this lesson observational data depicted a more teacher centred approach to teaching and learning. Previously students had prepared for the interaction assessment by taking notes from the teacher and writing practice sentences which they could memorise and say in the assessment. During classroom observations the learning mainly centred around the teacher explaining meanings of characters from the vocabulary list, translations, writing practice sentences with grammatical structures and completing practice listening and reading comprehension examinations.

Byram (2014), Newton (2014), and Liddicoat and Scarino (2013) discuss social interaction as an important strategy for drawing on diversity in the classroom. In this case study all three participating students are from different cultural backgrounds. There is no evidence in the data showing reference to or interacting with cultural diversity.

There is evidence that students engage in some genuine social interaction (iCLT Principle 2) in this classroom. The implications of further developing iCLT Principle 2 within the language classroom will be explored in the discussion.

\section{iCLT Principle 3: iCLT encourages and develops an exploratory and reflective approach to culture and culture in language}

iCLT Principle 3 recognises that learning and understanding culture goes well beyond studying factual knowledge. Exploration and reflection of cultural experiences provides students with the opportunity to decentre and examine perspectives of others and how others might perceive their world (Conway \& Richards, 2014). Principle 3 aims to develop critical awareness of both one's own and other societies (Newton et al, 2010), and in doing so aims to replace cultural stereotypes with more 'empathetic and self-aware perceptions and attitudes (Kramsch, 2006, p. 107).

Repeatedly, the data show that students actively explore and reflect culture and culture in language and make explicit comparisons and connections between languages and cultures (Principle 4) independently and outside of class. As an example, Excerpt 3.1 below provides an example of Lucy discussing opportunities to observe Chinese culture in class which have later led to her reflection on environmental and political issues. 
(3.1) Lucy talks about some of her reflections about Chinese culture after watching a documentary in class.

(00:01:03)

1 Lucy: $\quad$ we do have cultural sessions where we watch like a

'Bite of China' ( a Chinese made documentary about the different culinary traditions in China)) and stuff.

2 Researcher: Do you talk about it or do you just watch it?

3 Lucy: $\quad$ No we just watch it

$4 \quad$ it is interesting though the differences between the Chinese

$\rightarrow \quad$ food and NZ food but it is not really

$5 \quad$ I don't know they portray the Chinese people as being

$\rightarrow \quad$ really like all living in the country

6 and they make it look really green and clean which is not

$\rightarrow \quad$ true either.

7 Then I remember at the start of year 10

8 I did a poster

9 this is kind of unrelated

10 I did a poster on the Chinese president

11 I've forgotten his name

12 is it Xi Jin Ping?

13 and I did a poster on him and the Communist party and then

$\rightarrow \quad$ I got Excellence but I didn't see the poster again.

14 I think maybe because the Chinese Embassy people are

$\rightarrow \quad$ coming and it might not be good to have a poster about

$\rightarrow \quad$ Communism on the wall.

(00:01:58)

In Excerpt 3.1 there are many issues at play but due to space constraints I will only focus on those relevant to Principle 3. In line 1 Lucy mentions that her class sometimes watches a documentary about Chinese food as part of the cultural content in her class. Lines 2 to 14 suggest that although the content of the documentary is not discussed in class, she has noticed 'differences between the Chinese food and New Zealand food,' (once again a static view of culture). In response to my question 'do you talk about it?' (line 2), Lucy clearly states 'no we just watch it' (line 3). This response referring to the lack of reflection is representative of the pattern found throughout the data. The documentary, however, has made her reflect on environmental issues and Chinese politics. Lucy's reflection (lines 4 to 6 ) suggests that according to her perception of life in China, she believes the documentary does not portray reality. She feels that the documentary portrays 'Chinese people as ... all living in the country and they make it look all clean and green which is not true either' (line 6). These comments show that Lucy's views and ideas about China and Chinese people are 
informed by her own experiences outside of the CFL classroom through the media or discussing with her parents. If the class were to adapt an intercultural approach Lucy might have a place to discuss and explore her views and ideas with her peers and the teacher and potentially deepen her understanding of these complex issues.

Interview data repeatedly suggest that Lucy is interested in exploring and reflecting on Chinese politics. For example, in the present excerpt she discusses a poster about Xi Jin Ping and the Communist party that she made as part of a research project. Her comments suggest that she was surprised that although she received 'Excellence' she did not 'see the poster again' (line 13). Lucy reflects that maybe the poster was not displayed because the 'Chinese Embassy people' were 'coming and it might not be good to have a poster about Communism on the wall' (line 14).

Although she does not explicitly state her interest in Chinese politics, her learning Chinese has clearly been a trigger in thinking beyond Chinese language to Chinese Politics. During her initial interview, when asked what comes to mind when she thinks about Chinese culture her first response was 'like the government controlling stuff.' This comment suggests Lucy understands that Chinese culture extends well beyond Chinese "lanterns, dragons, and ... images of the Great Wall" (Orton, 2011, p. 161). The data further reveals that she has been influenced by her reading the novel Wild Swans (Jung Chang, 1991) ${ }^{15}$ as her mother recommended it to her when she first became interested in learning Chinese. It is not clear from the data, but this book might have partially influenced her later reflection (Excerpt 3.2) on why she no longer wants to visit China.

(3.2) Lucy discusses why she no longer wants to go to China in an interview.

1 Lucy: I don't know I always thought I wanted to go to China $\rightarrow \quad$ but now I don't actually want to go

2 Researcher: what makes you not want to go?

3Lucy: it is not that the culture is like

$4 \quad$ I still think the culture is really different to NZ so that would be

${ }^{15} \mathrm{~A}$ biographic and autobiographic novel which recounts the lives of three generations of females in China. 
really interesting

but then I don't really think I like what China is doing to the country.

I don't like how they are doing

like putting economic advancement before the environment, they are sort of like,

this might sound quite controversial but they are sort of like

$\rightarrow \quad$ this might sound

10 not their people but people are allowed to live anywhere,

11 but they've always got military bases in different countries

12 and it's like

13 I don't know hopefully they are not trying to take over the world!

$(00: 04: 31)$

Excerpt 3.2 shows Lucy accessing prior knowledge (which she is likely to have gathered from the media, literature, and discussing with her parents) as she reflects on why she no longer wants to travel to China. She reflects that experiencing the differences between New Zealand and Chinese culture 'would be really interesting' (line 4). However Lucy refers back to her dislike of Chinese political issues such as the economy, the environment and the military (lines 6 to 13) as playing a key role as to why she does not wish to go to China any longer.

In line 9 Lucy mentions that she is aware that what she has said is 'controversial.' This comment (line 9) highlights that she understands the comparative perspective and component (Principle 4) of reflection. In this interview Lucy does not explicitly say she would like to discuss these issues in class but she is concerned that her teacher 'might find it uncomfortable especially as our class is sponsored by the Embassy.' Later Lucy notes that language barriers between the students and the teacher can prevent class discussions.

Excerpts 3.1 and 3.2 present examples from the data which indicate that even without class time for exploration and reflection, students are likely to explore and reflect on culture outside of class as well and to an extent, culture in language based on their own experiences of the target language culture. Lucy's views are clearly influenced by what she experiences outside of the classroom. These opinions developed outside of class have changed her initial desire to travel to China and have ultimately changed her connection with Chinese language as she associates Chinese as the language she would use to go to China. One could argue that Lucy's views are based on cultural stereotypes which are 
presented in the media. Involving exploration and reflection in the classroom might have provided Lucy and other students with the opportunity to develop more awareness and critical understanding of these issues in both New Zealand and China. In decentring and exploring these issues from both sides Lucy might have had the opportunity to confront cultural stereotypes and 'replace cultural stereotypes with more empathetic and self-aware perceptions and attitudes' (Kramsch, 2006, p107, Newton et al, 2010).

iCLT Pinciple 3 encourages and develops an exploratory and reflective approach to culture and culture in language (Newton et al, 2010, direct quotation). Data from this study clearly shows that reflection does not happen as part of classroom practice but that students are naturally reflective and explore cultural material and ideas that they have met through learning Chinese at school in their own time. In Lucy's case, the repercussions of not including a reflective dimension in response to cultural content may have led to the forming of negative cultural stereotyping. Previous studies in ICLT (Conway \& Richards, 2014; Oranje, 2013, 2014; Sercu, 2006) have also shown that language classroom practices of reflection are misunderstood or lacking completely. The student voices from this study provide further evidence as to why the reflective dimension in the classroom plays a key role in developing intercultural competence.

\section{iCLT Principle 4: iCLT fosters explicit comparisons and connections between languages and cultures}

Principle 4 emphasises the importance of making comparisons and connections between cultures and languages in developing intercultural competence in the classroom. In comparing and connecting between languages and cultures, an intercultural approach recognises diversity in the classroom and looks to establish links beyond the classroom within the school, home and community (Liddicoat \& Scarino, 2013; Newton, 2014). When making comparisons and connections the intercultural approach encourages students and teachers to reflect and draw on prior experience and knowledge (Newton et al, 2010). The making of comparisons and connections needs to be ongoing, guided, and made explicit by the teacher, as it cannot be assumed that students 
will automatically embark on this process (Newton et al, 2010; Liddicoat \& Scarino, 2013).

Evidence in the data from this CFL class shows that students have some opportunities to explore the presence of Chinese culture beyond the classroom and to use Chinese language to connect with the wider school community. Catherine takes each of her classes to a Chinese restaurant once a year to provide the students with "a practical way for them to use chopsticks and greeting people in Chinese." (Interview, September, 2015). During this study Catherine's students also participated in a school wide activity to label parts of the school in different languages as part of International Languages Week celebrations. Classroom observation and stimulated recall data from this activity show the students enjoying the lesson making the signs and labelling the school. Samantha comments: 'I felt like it wasn't a class, and it was really kind of free you know ... it was more like a hanging out thing rather than like being involved with class.' (Stimulated recall, August, 2015). Whilst this type of activity is enjoyed by the students, the data suggests that these activities are stand alone events and not a regular part of class. These events tend to just happen rather than forming part of a continuous process of connecting, comparing, and reflecting.

Both Samantha and Lucy regularly compare and make connections with their own experiences of language and culture outside of class time. Excerpt 4.1 provides an example of Samantha comparing her experience of being Korean and living in New Zealand with her experience of learning Chinese in Catherine's class.

(4.1) Samantha discusses her general ideas about culture in relation to learning CFL in her first interview.

(00:00:07)

1 Samantha: So I guess I'm a little bit different to other Kiwis

$\begin{array}{ll}\rightarrow & \text { because I'm Korean so I mean I kind of relate more to what Ms Su } \\ \mathbf{2} & \text { says because I understand some of the cultures, } \\ 3 & \text { like 哪里哪里nalinali }{ }^{16}, \\ 4 & \text { we've got that kind of thing as well. } \\ & \text { Yeah and just like in general some of the words are almost the }\end{array}$

16 哪里哪里 nalinali is an expression used to show a modest acceptance of a compliment. 
same, and so I think culture is pretty important in learning a language.

I think it makes it a whole lot easier and I can relate to that and I can see the difference between my culture and Chinese culture and see the differences and similarities.

(00:00:49)

Line 1 shows Samantha comparing herself to both her New Zealand classmates and her Chinese teacher. She views her understanding of Chinese culture as being 'different to other Kiwis (line 1)' and perhaps because she is Korean she is more able to 'relate to what Ms Su says (line 1)'. Samantha feels she can relate to Chinese culture relayed by Ms Su because she has noticed that some aspects of Korean language (line 4) and culture, such as how to accept compliments (line 2), are similar to Chinese language and culture. Samantha says 'I think it makes it a whole lot easier and I can relate to ... and see the differences and similarities (line5). Line 5, implies that, perhaps unconsciously, she understands that comparing differences and similarities between languages and cultures enables one to more easily 'interact across cultural boundaries '(Byram, 1997, p. 7).

Excerpt 4.1 shows Samantha engaging with 'noticing' and 'comparing', two of the four inter-related on-going processes discussed by Liddicoat and Scarino (2013) for developing the intercultural language learner. Excerpt 4.2 provides further evidence of Samantha noticing and comparing.

(4.2) Samantha talks about cultural content from an exam question covered in class.

(00:04:04)

1 Researcher: have you had any cultural discussions in class apart from the movie?

2 Samantha:

Well we had, on the reading passage it said about the 红包 ${ }^{17}$

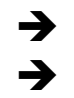
bao um Ms Su told us about the Chinese culture about like how people give money in the bag.

3 Researcher: and did you have a little chat about hong bao? Did you go into heaps of detail or was it just a kind of passing thing?

5 Samantha: $\quad$ Yeah I mean it is like parents give money to children $\rightarrow \quad$ basically,

6 because it was like the same thing that we do in Korea as well.

17 红包 hong bao is a small red packet or envelope containing money that Chinese children receive at Chinese New Year from family members. 
7 Researcher: $\quad$ oh cool do you have hongbao in Korea as well?

8 Samantha: not hongbao but we like get money.

9 Reseacher: [is Hongse like]

10 Samantha: [Hongse is red]

11 Researcher: but is it like good luck in Korea as well?

(( it refers to the colour red - hongse))

12 Samantha: no

13 Researcher: and did you talk about how you have it in Korea in class or $\rightarrow \quad$ was it more your own reflection?

14 Samantha: my own reflection.

(00:05:16)

Samantha mentions that as part of a practice reading passage her teacher tells the class 'about the Chinese culture about how people give money in the bag' (line 2). Here 'the Chinese culture' is portrayed as static knowledge. However, Samantha has made the connection with experiences of her own native Korean culture (line 5). On being asked about the tradition in Korea, she discusses the similarities and differences (lines 8 to 12) of this New Year's tradition. Similarly to evidence of Principle 3 in the data, Samantha says she made the connection through her own reflection rather than explicit class discussion.

With regards to Liddicoat and Scarino's (2013) model for developing the intercultural language learner both Excerpts 4.1 and 4.2 show tangible examples of noticing and exploring. Without explicitly involving the other two interrelated processes (reflecting and interacting), the possibility of actively developing intercultural competence is less likely. Lack of explicit guidance in comparing and reflecting can lead to confusion or negative effects on intercultural attitudes (Newton et al, 2010) as demonstrated in Lucy's comment: it is kind of hard to separate them as Ms Su as a person and Ms Su as Chinese ... so I don't know whether some stuff I think of as weird is because it is just her or her culture. (Stimulated recall, September, 2015) The ongoing process of noticing, comparing, reflecting and interacting within the language classroom context provides students with opportunities to value each others' cultures, use language to explore culture and find personal ways of engaging in intercultural interaction (Liddicoat \& Scarino, 2013). 


\section{iCLT Principle 5: iCLT acknowledges and responds appropriately to diverse learners and teaching contexts}

Principle 5 recognises that teaching a language from an intercultural perspective acknowledges and embraces the diverse cultural and linguistic backgrounds of the learners as well as the "values on which New Zealand's cultural and institutional traditions are based" (Ministry of Education, 2007, p. 10; Newton et al, 2010; Newton, 2014). Principle 5 also aligns with one of Ellis' (2005) ten principles for successful instructed language learning, which support teachers in the language knowledge strand of the New Zealand Curriculum. This Ellis Principle states: "Instruction needs to take account of individual differences in learners" (Ellis, 2005, p. 41). Individual difference is defined by Ellis (2005) as variability in aptitude. In relation to this Ellis Principle, Ellis (2005) underlines the importance of flexible approaches to teaching and learning. iCLT Principle 6 interpreted with this Ellis (2005) principle take into account: diversity in aptitude, cultural backgrounds, and learning contexts. The data collected in this case study reveal that there are occasional naturally occurring examples of Principle 5 in practice, specifically to do with acknowledging students as individuals.

Classroom observation data show Catherine relating to students on an individual level by praising and joking with students and thus relating to each student as an individual within a diverse group. Excerpt 5.1 below provides an example of Catherine engaging in this manner with Samantha:

(5.1) Samantha asks the teacher for help with vocabulary as she and her partner are practising for their speaking assessment.

(00:24:34)

$\mathrm{S}=$ Samantha

$\mathrm{C}=$ Catherine

((Samantha asks the teacher))

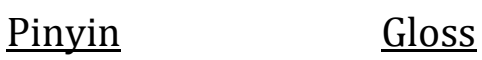

$1 \mathrm{~S}$ : how do you say I'll think about it? 我想一想?

2 C: let me listen, ah 我想一想让我想一想 wo xiang yi xiang, 'I'll think rang wo xiangyi xiang about it

let me

think

about it' 
$\rightarrow$ you can say “如果你有问题给我打电话' rugou ni you wenti 'if you gei wo da dian hua have any problems give me a call'

((Catherine makes a friendly aside to Samantha about her friend $))$ 3 这是一个好朋友! zhe shi yi ge hao 'she is a good friend!'

4 S: 我同意! pengyou

'I agree!'

((both Samantha and Catherine laugh)) (00:25:08)

Lines 1 shows Samantha is comfortable asking her teacher for individual help, suggesting that time for developing strong teacher-student relationships has been invested by both parties. Evidence of how Catherine establishes individual relationships with her students is found in line 3 (这是一个好朋友！'She is a good friend!'), when Catherine makes a friendly comment about her friendship with Samantha and her classmate. In mentioning friendship, Catherine connects with Samantha and her classmate as individuals and shows interest in their lives beyond the classroom. In developing strong relationships with students individually, Catherine demonstrates how teacher 'investment' (Darvin \& Norton, 2015; Norton Pierce, 1996) in students can be helpful in engaging individual learners in the language classroom. The ways and time she has developed and spent investing in building individual teacher-student relationships result in increased student interest and motivation.

While, the data show Catherine relating to students as individuals, from an intercultural stance, the data indicate that diverse linguistic and cultural backgrounds of the learners in the classroom are not explicitly acknowledged and embraced. As mentioned in the findings of Principles 2 and 4, this classroom is culturally diverse.

In Kelly's case, a lack of feeling connected with the target language beyond the classroom (Principle 4) underpinned her decision to change from learning Chinese to Italian at her new school in the United States. When asked why she decided not to continue with Chinese, she responds:

Well it is because my Dad is already not fluent but he is very into learning it, he is quite good about having conversations, so it is like the idea that like 
every day I could come home and I could have a conversation with him about what I've learned in Italian, and it would be a more oral way of learning it I think because I don't really get a chance to talk in Chinese outside of Chinese. (Interview, June, 2015)

Kelly's father is passionate about learning Italian and speaking it at home. Being able to learn Italian at school and then to come home and practise speaking Italian with her father appeals to her. Therefore, she has chosen to change from learning Chinese to Italian when she moves back to the United States, as she feels she will have more opportunities to use Italian outside of the language classroom.

In an intercultural approach, the teacher is able to incorporate and draw on the complex and changing social identities of the students. In Kelly's case, an intercultural stance in the classroom, which acknowledges and responds to the family interest in language learning, might help provide pathways for her to explore and share both her father's interest in Italian and her own learning of Chinese. These intercultural and interconnected pathways enable students to extend their language learning beyond the classroom, potentially encouraging life-long, self-managed, and global minded learners - traits which embody intercultural education (Liddicoat, 2011; Sercu, 2004). Perhaps if Kelly had been provided with intercultural strategies for exploring the linguistic and cultural boundaries between Chinese, Italian and her own cultural and linguistic background (Byram, 1997), she might have felt a greater sense of connection with learning Chinese and more invested and motivated to carry on studying CFL.

With regards to student and teacher investment (Norton Pierce, 1996), iCLT Principle 5 (iCLT acknowledges and responds appropriately to diverse learners and teaching contexts) provides a useful frame for developing a deeper sense of investment in language teaching and learning. Norton Pierce (1996) argues that the student's investment in learning a language is what ultimately leads to the student wanting to use the language. In order to achieve this sense of investment, Norton Pierce (1996, p. 26) advises that the diverse lived experiences and social identities of the learners need to be included in second language education. In drawing on cultural and linguistic diversity in the 
classroom (Principle 5), intercultural pedagogies provide a natural platform for including and involving the social identities of the learners.

\section{iCLT Principle 6: iCLT Principle 6 emphasises intercultural competence rather than native speaker confidence}

Principle 6 recognises that developing interculturally competent speakers is a more realistic and desirable goal than developing communicative competence, which ultimately aims to develop native-like speakers and cultural assimilation. The intercultural stance allows learners to hold on to and learn more about their own culture whilst developing skills to communicate across linguistic and cultural boundaries (Byram, 1997; Newton et al, 2010). In addition, Principle 6 provides another reason to move away from the native-like speaker model by acknowledging that cultural and linguistic norms of native speakers are not identical, but are constantly changing (Kramsch, 1993; Newton et al 2010).

There is a small amount of evidence in the data that Principle 6 occurs occasionally naturally in a classroom which does not consciously employ intercultural pedagogies. Excerpt 6.1 below shows Samantha noticing that there are many variations of Chinese within China and therefore beginning to understand the complexity of how 'native speaker' is defined.

(6.1) Samantha discusses cultural aspects she has noticed from discussions in class

(00:01:48)

1 Samantha:

2

3

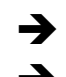

4

5

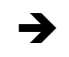

6

7

$\rightarrow$

8 Researcher: and we also talk about China itself

like you know how there are different dialects in China, like Ms Su once told us like how her husband says 'niu nai,' 'milk' in a different way so that is like getting to know other different versions of Chinese, I guess that kind of counts as culture as well and this is out of Chinese ((meaning Chinese class)) I've got quite a lot of Cantonese friends but they can not speak Chinese at all but like Ms Su says that Mandarin is an official language so they should know it but actually they only know Cantonese I kind of find it quite interesting how some people can't understand their own people.

Do you have different versions of Korean in Korea? 
yeah we've got dialects but we can pretty much understand (00:02:50) each other.

Samantha reflects on what she has heard about Chinese dialects from her teacher (lines 2 and 3). She specifically remembers a story Ms Su has told about her husband's pronunciation of specific words (line 3). Interestingly, the example Samantha remembers comes from the one the teacher has provided from her personal experience (line 3). This links to Principle 4 which stresses the important role of making connections between different cultures in developing intercultural competence. In lines 5 to 9, Samantha makes further connections with her experience of Cantonese speaking friends outside of class as she discusses her understanding of native speakers.

However, once Samantha starts to discuss her understanding of Chinese and how it is spoken in China, it appears that there are many complex cultural and political issues for her still to grasp. Samantha expresses her surprise that her Cantonese-speaking friends cannot speak 'Chinese at all' (line 5). The data imply that she does not fully understand that Cantonese and Mandarin are both varieties of Chinese.

Though not explicit in the data, Samantha's understanding of what is Chinese could be partly due to the teacher's portrayal of Mandarin as the official language, and therefore Chinese people 'should know it' (line 6). During class, Catherine jokingly calls her Chinese 'BBC Chinese' (Classroom observation, July, 2015). The implied meaning behind 'BBC Chinese' is that Catherine's use of Mandarin is a perfect version of Putonghua - modern standard Mandarin (the official language throughout China). As Putonghua originally comes from the Northern part of China, people growing up in the North of China have a natural advantage in mastering China's official language. These types of comments might be at play when Samantha expresses that she finds it 'quite interesting that some people can't understand their own people' (line 7). Samantha's later comments show her noticing other dialect related parts of her teacher's speech, such as the strong ' $r$ ' sound that is typically heard in the north of China. If this classroom were to adopt an intercultural approach, all aspects of regional difference in speech which Samantha has noticed would provide an excellent 
platform for developing intercultural comparisons, reflection and deepening of understanding which may lead to further developing intercultural competence.

As seen in Excerpts 2.1 and 2.2, the data provide evidence of Samantha and her classmate engaging in genuine social interaction (Principle 2). This happens because the teacher has provided students the opportunity to interact freely with one another in Chinese. Later on in the same class however, the teacher spends ten minutes uninterrupted performing a model dialogue. Excerpt 6.2 below provides a short example of this modelling:

(6.2) Catherine interrupts the students fifteen minutes into the class to model a dialogue.

$(00: 12: 42)$

\begin{tabular}{|c|c|c|c|}
\hline \multicolumn{4}{|c|}{$\underline{\text { Pinyin }}$} \\
\hline 1 Catherine: & \multicolumn{3}{|c|}{ just pretend I'm your } \\
\hline$\rightarrow$ & \multicolumn{3}{|c|}{ partner, } \\
\hline 2 & \multicolumn{3}{|c|}{ I can do something } \\
\hline$\rightarrow$ & \multicolumn{3}{|l|}{ verbally, } \\
\hline 3 & \multicolumn{3}{|c|}{ anyone want to ask me } \\
\hline & \multicolumn{3}{|c|}{ something or? } \\
\hline \multicolumn{4}{|c|}{ ((one student asks how she is in Chinese $))$} \\
\hline 4 & 我很好你呢 ***? & $\begin{array}{l}\text { wo hen hao } \\
\text { ni ne }\end{array}$ & $\begin{array}{l}\text { 'I'm well } \\
\text { and you?' }\end{array}$ \\
\hline 5 & 你知道吗? & ni zhidao ma & $\begin{array}{l}\text { 'do you } \\
\text { know?' }\end{array}$ \\
\hline 6 & \multicolumn{3}{|l|}{ if you don't ask me } \\
\hline$\rightarrow$ & \multicolumn{3}{|l|}{ anything and stop } \\
\hline 7 & \multicolumn{3}{|l|}{ I would ask you } \\
\hline$\rightarrow$ & \multicolumn{3}{|l|}{ 你知道吗 } \\
\hline$(($ then translates $))$ & \multicolumn{3}{|l|}{ you know? } \\
\hline 8 & 我假期的时候去 & wo jiaqi de shihou & 'I went to Beijing \\
\hline$\rightarrow$ & 中国北京了！ & $\begin{array}{l}\text { qu zhong guo } \\
\text { Beijing le }\end{array}$ & $\begin{array}{l}\text { China in the } \\
\text { holidays!' }\end{array}$ \\
\hline 9 & \multicolumn{3}{|c|}{ I can say that straight } \\
\hline$\rightarrow$ & \multicolumn{3}{|c|}{ away and without } \\
\hline $\begin{array}{l}\overrightarrow{7} \\
10\end{array}$ & \multicolumn{3}{|c|}{ being asked. } \\
\hline 11 & \multicolumn{3}{|c|}{ feel like I can't wait } \\
\hline$\rightarrow$ & \multicolumn{3}{|c|}{ to share you know things ... } \\
\hline 12 & \multicolumn{3}{|c|}{ 你知道吗?*** } \\
\hline$\rightarrow$ & \multicolumn{3}{|l|}{ 假期的时候 } \\
\hline$(($ She translates $))$ & & & \\
\hline 13 & \multicolumn{3}{|l|}{ over the holiday } \\
\hline
\end{tabular}




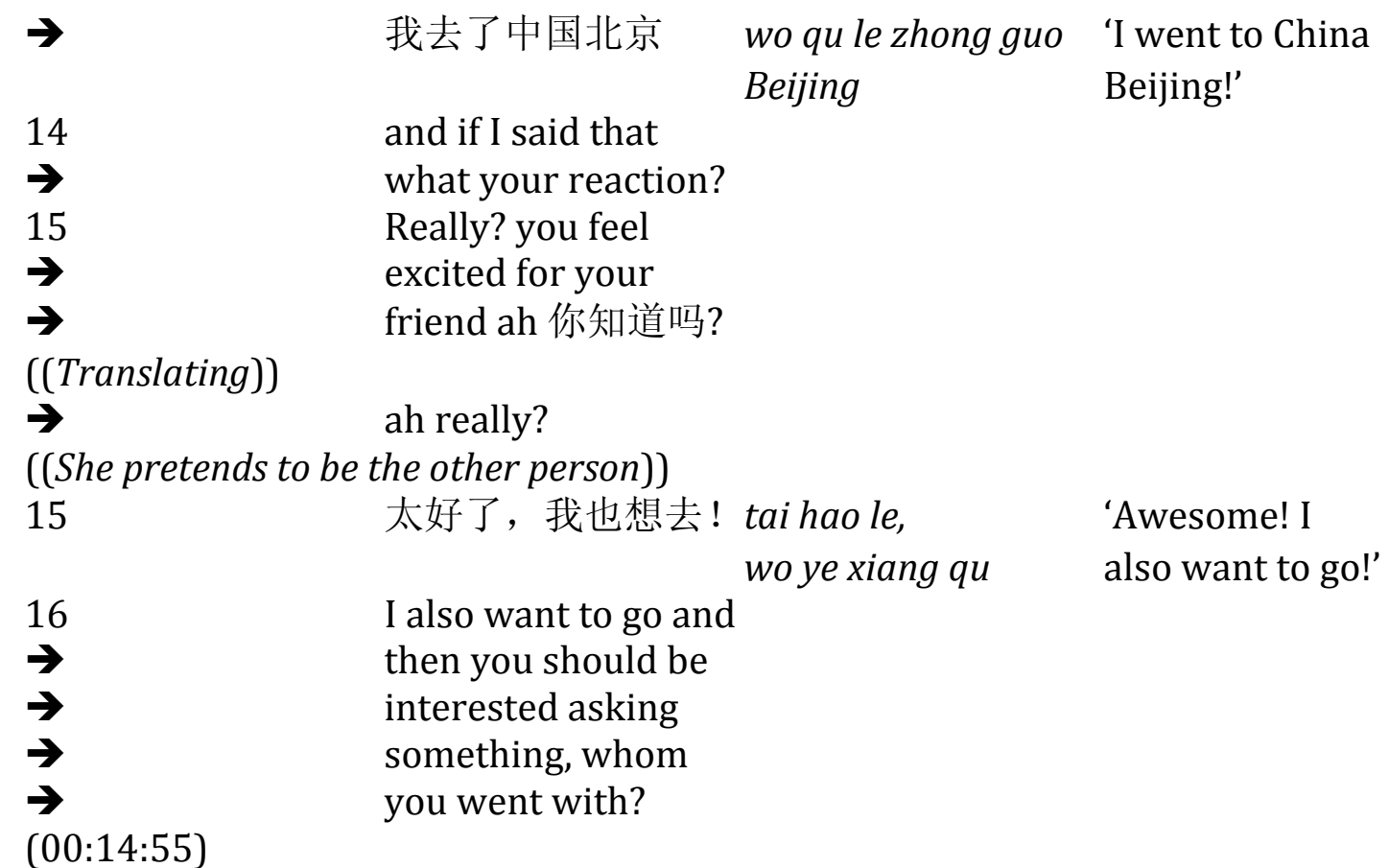

Throughout this excerpt, Catherine enacts a conversation in which she plays the role of both students participating. She goes into precise detail including small comments such as '你知道吗? (do you know)' (lines 5, 7, 10, 12), and provides examples of specific content (line 13) and responses from the second speaker (line 15). As she talks through what she is saying, she instructs the students metadiscursively how to conduct the conversation, 'you should be interested asking something, with whom you went with?'(line 16). Catherine does not explicitly say to the students that they should try to copy her example, but after the ten minutes of explanation, there is evidence of students imitating what she has said. Samantha's partner, who was not transcribed, stops her practice interaction with Samantha several times to include elements of the teacher's example. From a second language acquisition point of view, Catherine's model dialogue is very effective as she is providing students with comprehensible input (Ellis, 2005; Krashen, 1982), which they then output into their practising (Ellis, 2005). However, her model conversation may send the message that successful communication is achieved by sounding like the native speaker model.

There is also some evidence that Lucy is apprehensive about not sounding correct or native speaker-like. Excerpt 6.3 below shows her sharing her concerns with a classmate whilst practising for the speaking assessment. 
(6.3) Lucy and her friend are planning a practice dialogue about holidays in class.

(00:08:17)

1 Lucy: $\quad$ 不好! ${ }^{18}$

((Sounding frustrated $)$ )

2 what, I need to remember all of these sentence structures ...

3 who, how, what. Who, when, what. Who, when, where, what.

$4 \quad$ It is so weird how the what is last don't you think?

$5 \quad$ Like so they don't actually know what you are doing until the end

$\rightarrow \quad$ of the sentence.

6 It's like "I, in the holidays, in Christchurch, played the piano"

(00:08:50)

In line 1 Lucy uses the target language to voice her frustration and then complains to her friend that she finds it challenging to remember the sentence structures (lines 2 and 3). Her sense of frustration and stress in remembering the grammatically correct order (lines 2 and 3) suggests she feels she needs to say her sentence grammatically correctly to communicate successfully. She comments on finding Chinese sentence structure 'weird' (line 4) and then illustrates why she finds it strange with an example of an English sentence with Chinese syntax (line 6). By mentioning that she finds Chinese syntax 'weird', it is possible that Lucy does not feel comfortable using Chinese word order as it is different to her linguistic norm.

Later in the data, when asked what Lucy was thinking during the long example dialogue performed by the teacher (Excerpt 6.2), Lucy says, "I was worried she was going to ask me to do an example in front of the class" (Stimulated recall, September, 2015). When I asked why she felt worried she replied, “Just because I hadn't really finished writing out my plan so I didn't really want to be put on the spot and be embarrassed" (Stimulated recall, September, 2015). Lucy's comments from the stimulated recall further suggest she does not feel comfortable producing language spontaneously which has not yet been written out and checked.

iCLT Principle 6 stresses the importance of intercultural competence in language use rather than native-speaker like competence (Newton et al, 2010). Intercultural pedagogies encourage students to use the foreign language for

18 不好! - bu hao 'not good!' 
effective communication with people from diverse backgrounds. Principle 6 acknowledges that making mistakes are a normal part of speaking other languages. In Lucy's case, the intercultural lens on using the target language for effective communication might have relieved some of the stress she felt when speaking in Chinese. Intercultural exploration and comparisons of grammar and syntax between languages (iCLT Principles 4 and 5) might also have demystified the 'weird' (Excerpt 6.3, line 4) Chinese sentence structure.

\section{The overall picture from the findings}

The overall emerging picture of this CFL classroom (which does not have explicit knowledge of ICLT) depicts a classroom environment with occasional naturally occurring instances of ICLT. Many existing teaching and learning practices in the class could incorporate an intercultural dimension with appropriate teacher training in intercultural pedagogies. Catherine, the teacher, views culture and language as connected. She is aware that national assessments and professional discussions now focus more on culture than when she trained, and her classroom practice already includes a cultural focus.

Students in the class, Lucy, Kelly, and Samantha are interested in culture and engage in some intercultural processes such as comparing and reflecting without being prompted by the teacher. However, the overall findings also indicate that without explicit inclusion of intercultural pedagogies during class (involving discussing, comparing, connecting outside experiences with those in the classroom and reflecting), the skills, knowledge and traits which make up intercultural competence are not likely to evolve. Furthermore, we see that without a deliberate intercultural dimension allowing students to discuss and process culturally and linguistic related ideas and opinions, students can develop negative stereotypes and cultural misunderstandings.

\section{DISCUSSION}

To meet the demands of our increasingly multicultural societies, many school curriculums and educational policies worldwide now include developing 
intercultural competence across the curriculum as part of a teacher's job description. However, the findings of this study and previous research show that teacher awareness and ability to practice pedagogies that promote the development of intercultural competence are not commonplace. In order to help bridge the gap between theory of IC and practice in the curriculum area of learning languages, this study set out to provide a rich description of naturally arising opportunities available for developing intercultural communicative competence through ICLT in a New Zealand CFL classroom. Establishing naturally occurring intercultural opportunities in the classroom provides a starting place for further developing pre-existing classroom practices with an intercultural lens. As part of this rich description, the current study has sought to explore the views of the teacher and students with regards to teaching and learning language and culture, and to examine how this particular CFL classroom fits into the overall picture of classroom practices of ICLT research in classrooms carried out so far.

The naturally arising opportunities for ICLT from the study are summarised and presented through Newton et al's (2010) framework of six principles of iCLT in Table 2 directly below:

Table 2

\begin{tabular}{|l|r|}
\hline $\begin{array}{l}\text { Newton et al's (2010) six principles for } \\
\text { intercultural communicative language } \\
\text { teaching (iCLT) }\end{array}$ & $\begin{array}{l}\text { Examples of naturally arising moments } \\
\text { of Newton et al's (2010) iCLT principles } \\
\text { in practice }\end{array}$ \\
\hline $\begin{array}{l}\text { iCLT Principle 1: iCLT integrates language } \\
\text { and culture from the beginning }\end{array}$ & $\begin{array}{l}\text { The language use and actions of } \\
\text { the native speaker teacher in the } \\
\text { classroom model the } \\
\text { interconnectedness of language } \\
\text { and culture as the teacher adapts } \\
\text { her language and behaviour } \\
\text { according to the context. } \\
\text { The teacher regularly } \\
\text { translanguages between Chinese } \\
\text { and English which demonstrates } \\
\text { how language and culture work } \\
\text { together as complex and dynamic } \\
\text { practices. } \\
\text { The teacher teaches the students } \\
\text { about cultural context and } \\
\text { meaning when teaching } \\
\text { vocabulary. }\end{array}$ \\
\hline $\begin{array}{l}\text { The teacher provides students } \\
\text { with opportunities to engage in }\end{array}$ \\
\hline $\begin{array}{l}\text { iCLT Principle 2: iCLT engages learners in } \\
\text { genuine social interaction }\end{array}$ & \\
\hline
\end{tabular}




\begin{tabular}{|l|l|}
\hline & $\begin{array}{l}\text { genuine social interaction with } \\
\text { classmates, for example in } \\
\text { preparing for speaking } \\
\text { assessments. }\end{array}$ \\
\hline $\begin{array}{l}\text { iCLT Principle 3: iCLT encourages and } \\
\text { develops an exploratory and reflective } \\
\text { approach to culture and culture-in- } \\
\text { language }\end{array}$ & $\begin{array}{l}\text { Students explore and reflect on } \\
\text { Chinese culture outside of class. }\end{array}$ \\
\hline $\begin{array}{l}\text { iCLT Principle 4: iCLT fosters explicit } \\
\text { comparisons and connections between } \\
\text { languages and cultures }\end{array}$ & $\begin{array}{l}\text { Students compare and make } \\
\text { connections between languages } \\
\text { and cultures independently } \\
\text { outside of the classroom. }\end{array}$ \\
\hline $\begin{array}{l}\text { iCLT Principle 5: iCLT acknowledges and } \\
\text { responds to diverse learners and learning } \\
\text { contexts }\end{array}$ & $\begin{array}{l}\text { The teacher knows her students } \\
\text { well and invests time to get to } \\
\text { know students on an individual } \\
\text { basis. }\end{array}$ \\
\hline $\begin{array}{l}\text { iCLT Principle 6: iCLT emphasises } \\
\text { intercultural communicative competence } \\
\text { rather than native-speaker competence }\end{array}$ & $\begin{array}{l}\text { One student shows awareness of } \\
\text { some of the complexity } \\
\text { surrounding the notion of the } \\
\text { Chinese native speaker. }\end{array}$ \\
\hline
\end{tabular}

The summary in Table 2 shows that the naturally arising examples of intercultural classroom practices, skills and attitudes encompass all six of the principles from Newton et al's (2010) framework. In the teacher's case, the majority of natural examples of intercultural practice are categorised within iCLT Principle 1. The teacher's natural presence as a Chinese native speaker in the classroom provides students with many examples of culture and language at play through her interactions and behaviour. The teacher's use of translanguaging also demonstrates to students how one can use language to move between linguistic and cultural boundaries. Both classroom observations and interview data show the teacher involving cultural context and meaning when teaching vocabulary.

Table 2 indicates that students also engage in some naturally intercultural behaviours without explicitly being asked to do so by the teacher. All three participating students demonstrated some level of intercultural interest, and some ability to compare and reflect about what they had been learning in and out of Chinese class.

However, although there is evidence of naturally occurring incidents of ICLT, the overall picture found in this case study reinforces the theory of developing intercultural competence in language education. ICLT theory stresses that without explicit and regular inclusion of intercultural pedagogies, 
the knowledge, skills, attitudes, dispositions, and values which embody intercultural competence are unlikely to be developed in the language classroom (Byram, 1997, 2014; Coperías Aguilar, 2007; Kramsch, 1993; Liddicoat \& Scarino, 2013; Liddicoat, 2014; Lo Bianco et al, 1999). Applicable to all languages, this finding is also particularly important for the literature surrounding the treatment of culture in CFL.

Based on her experience as a CFL educator, Xing (2006) claims that cultural competence in CFL speakers develops alongside language proficiency and that therefore the main focus of CFL should remain on language proficiency. Similarly, Danison (2013) and Diaz (2013) encounter resistance to teaching culture or including the intercultural dimension in tertiary level CFL classes, as language proficiency alone was considered to be more important. Findings of the current study contradict the above notion of increased language proficiency leading to intercultural competence. A few select examples from the findings have been chosen to illustrate how the explicit inclusion of intercultural pedagogies, in particular the reflective dimension, might have resulted in students in this study gaining deeper intercultural understanding and subsequently developing intercultural competence in the CFL classroom.

During Lucy's three years of studying CFL at high school, her attitude to learning Chinese has changed. When she first started learning Chinese, she felt positive and particularly motivated to go to China to experience Chinese language and culture. As she discovered more about Chinese culture, through reading outside of class and perhaps through discussion with her parents, she developed strong feelings in response to Chinese political issues, such as the economy and the environment, which influenced her attitude towards learning Chinese. Lucy did not feel comfortable bringing up these issues during CFL lessons, though, and there is no evidence in the data of class discussions including comparisons and reflections with an intercultural focus. Her dislike of what she understood the Chinese political stance to be regarding these issues, led her to develop negative stereotypes and feel unenthusiastic about China and learning Chinese.

Had an intercultural lens been applied to this classroom, Lucy might have felt comfortable discussing these arising views, and had the opportunity to 
explore, discuss, compare and reflect on these issues with her teacher and peers. Class time for reflection may also have led to further discussion at home with her parents, essentially creating the chance for Lucy to develop a much deeper and critical understanding of these complex issues.

Deep and critical understanding involves being able to understand different perspectives. One main goal of developing intercultural competence in education is being aware of one's own culture(s) as well as other cultures and being particularly aware of the different cultural and personal lenses at play when trying to accept and understand others' behaviours (Asia Society, 2015; Bolstad et al, 2013; Byram, 1997; Chen \& Starosta, 1998; Liddicoat \& Scarino, 2013; Te Kete Ipurangi, Ministry of Education, 2015). When applied to Lucy's case, an example of the above mentioned goal being developed through intercultural exploration in the language classroom could involve the discussion of environmental issues. Adopting an intercultural stance would have enabled Lucy to critically explore, compare, connect, and reflect on the political handling of environmental issues in New Zealand in relation to those in China. Through discussion and reflection, Lucy may have, for example, realised that New Zealand also grapples with environmental issues and does not necessarily respond to these issues in better ways than China.

This issue could further combine linguistic and cultural exploration by inviting international students from China who attend the same school into class discussions or class collaboration with high school students in China through social media or email. Establishing connections beyond the classroom provides students with meaningful opportunities to engage in genuine social interaction (iCLT Principle 2) and more deeply explore cultural and linguistic boundaries (Byram, 1997; Newton et al, 2010; Newton 2014). The ability to more deeply understand one's own language and culture in relation to other cultures potentially breaks down cultural stereotypes and develops open-mindedness, empathy, and knowledge of one's self and others in human interactions; in other words - intercultural competence (Byram, 1997; Chen \& Starosta, 1998; Liddicoat \& Scarino, 2013).

Samantha's case provides another example of how an explicit intercultural approach in the classroom might lead to enhanced intercultural 
awareness. Data from this study show that student understanding of Chinese culture in the context of learning CFL is predominantly understood as static knowledge (factual, unchanging knowledge). In the data, students commonly refer to culture as comprising of festivals, food, tradition, and history. Student understanding of Chinese culture in class and student lived experiences of Chinese culture outside of class are not explicitly linked and integrated. In separating static knowledge learnt in class and dynamic experiential knowledge of Chinese culture, Samantha appears to have developed cultural stereotypes and some misconstrued ideas about Chinese language and China.

Data show Samantha finding it "strange" that her Cantonese-speaking friends cannot speak Chinese or understand Chinese. Once again, had the intercultural lens been applied to this example, Samantha would have had the opportunity to connect with and share her personal experiences of Cantonese speakers in the CFL classroom. With time for explicit class discussion, during which students are invited to draw on their personal experiences and reflect, Samantha might have had the opportunity to understand more deeply about the different Chinese languages spoken in China and the political role of Mandarin Chinese as the official language. The intercultural focus might extend to comparing the different official languages of New Zealand, how widely they are spoken and represented and also different languages and dialects found in her home country, Korea. In applying the intercultural perspective, Samantha would have the opportunity to gain a richer awareness of language and culture in China and her own cultural background of growing up in Korea and New Zealand.

The findings show that the students in this CFL class come from a range of cultural backgrounds, but this diversity is not actively recognised. In an interculturally orientated classroom, Chinese New Year traditions and explicit connections and comparisons with one's own culture might provide a starting point for students to understand and appreciate more about Chinese culture, the different diverse backgrounds of their classmates, and their own home culture. For example, one topic for a speaking assessment could be to discuss with a classmate how one's own family celebrates important festivals, what is enjoyable, and what are the similarities and differences between classmates and what students know about festivals in China. 
Catherine, the teacher of the class, has not participated in any professional development or training in intercultural pedagogies to date. According to research of ICLT beliefs and practices in the New Zealand language classroom (Conway et al, 2010, 2012; Conway \& Richards, 2014, East, 2012; Oranje, 2013, 2014), Catherine's lack of knowledge about ICLT matches with the general picture of language teachers in New Zealand to date, namely that ICLT is not widely well understood and practised. However, studies by Conway et al $(2012,2014)$ have shown that teacher awareness of ICLT in New Zealand is growing gradually.

Although Catherine is unaware of ICLT, her views about teaching language and culture are well disposed to the intercultural approach. She believes that language and culture are inextricably linked and that the inclusion of culture in the CFL classroom is an essential part of learning Chinese. In this way Catherine's beliefs are more positively aligned with ICLT than other native speaker CFL teachers discussed in the literature. For example, Danison (2013) studied a CFL university classroom with a native speaker teacher who was unwilling to connect language and culture. The teacher appeared to find cultural questions annoying and time consuming when there was "a lot of language to learn" (Danison, 2013, p. 101). Similarly, Diaz (2013), who conducted participatory action research (PAR) aiming to work collaboratively with university lecturer to develop an intercultural dimension into Chinese and Italian programmes, found that the native speaker CFL lecturer viewed the cultural and intercultural dimension as too time consuming. This lecturer believed that language and culture were somewhat related but that grammatical accuracy was more important for communication and therefore her course was "linguistically driven" (Diaz, 2013, p. 101). Catherine's existing beliefs that language and culture are connected suggest that she might respond more positively to learning about an ICLT approach.

Catherine's views on the connectedness of language and culture are similar to the teacher views found in Sercu (2006). Sercu's (2006) extensive survey found that teachers throughout Europe and Mexico were generally well disposed to the idea of teaching intercultural competence in language lessons, 
but their knowledge and skill levels were better equipped for teaching culture in the communicative approach.

Similarly to the teachers in Sercu's (2006) study, Catherine's current teaching practices tend towards treating culture as static and factual knowledge. Her classroom practices include many cultural activities, often in the form of cultural sessions. Catherine's cultural activities such as showing films, creating projects about traditional Chinese festivals and food could involve students engaging in genuine social interaction in both the target language (and other languages present in the class) and be developed into opportunities for intercultural exploration if Catherine were to incorporate a reflective dimension. Comparing, connecting and then reflecting are integral processes in developing intercultural competence (Byram, 1997; Liddicoat \& Scarino; 2013; Newton et al, 2010) which allow students to decentre from their cultural norms and demystify the otherness or strangeness of different cultures (Liddicoat \& Scarino, 2013).

According to the literature of teacher awareness and practices of ICLT, the picture we have in Catherine's classroom is comparable to many language classrooms in New Zealand and elsewhere. Therefore one might assume that many other language classrooms have some inherent ICLT practices but not sufficient awareness of ICLT that they explicitly use intercultural pedagogies with the aim of developing intercultural competence alongside linguistic competence. With more awareness of ICLT and how to implement intercultural pedagogies in teaching languages, New Zealand language teachers like Catherine will be able to maximise the many opportunities and resources already available in the language classroom for developing intercultural competence in students.

Furthermore, the focus on establishing links beyond language lessons and the acknowledgement and responsiveness to diversity that an intercultural approach brings to the classroom, have the potential to help students develop a stronger sense of connection and relevance in language learning. This sense of connection and relevance may lead to students deciding to continue with language study beyond the compulsory stage. The findings of the current study show two students feeling disconnected with learning Chinese, which in part contributed to both students' decisions to discontinue studying Chinese the following academic year. New Zealand and other English-speaking countries 
continue to struggle with retaining students learning languages beyond beginner level (East, 2015, 2009, 2008). If ICLT were to be practised widely in New Zealand language classrooms, students might not only develop stronger intercultural skills, but also feel a greater sense of connection and understanding of the relevance in learning a language. This sense of meaningfulness found in learning a language could ultimately lead to more students continuing with language study.

Alternatively, if the number of students learning languages at school and tertiary level continue to decline, an ICLT approach to language teaching is arguably even more favourable. If most students are only to complete one or two compulsory years of foreign language study, developing curiosity and tolerance towards other cultures and gaining a "deeper understanding of one's own culture and the ways in which cultures may vary" (Liddicoat, 2008, p. 280) may be the most preferable and transferable learning outcomes of a short language course.

The need for humans to be culturally self-aware, whilst respecting, accepting, valuing and successfully communicating with people from different cultural backgrounds (Chen \& Strarosta, 1998; Liddicoat \& Scarino, 2013) is going to increase in our globalised world. Learning languages is a key area in education for developing these qualities which enable intercultural competence. So far, language education in schools has not yet realised its full potential in developing intercultural competence within the classroom. Teacher awareness of the importance of developing intercultural competence and ability to use ICLT in the language classroom are crucial in making the most of this educational opportunity.

\section{RECOMMENDATIONS}

In order for language teacher awareness and classroom practices of ICLT to grow, support for teacher professional development in ICLT needs to be promoted by several parties. Firstly, existing teacher professional development programmes focusing on ICLT in New Zealand must continue to be funded by the Ministry of Education. The Ministry of Education, school principals, and 
curriculum support leaders such as national language advisors should encourage all language teachers to participate in these programmes. As a large proportion of CFL teachers are native speakers, availability of some ICLT training courses and ICLT resources delivered and written in Chinese would help increase teacher understanding of new pedagogies. More opportunities for regular collaboration and sharing of intercultural experiences between non-native and native speaker CFL teachers would help promote general teacher awareness of ICLT and the development of quality resources produced in Chinese.

Further projects or research driven by teachers exploring the 'what' and 'how' of ICLT in the language classroom would provide language teachers with a larger tool kit of ideas for practical implementation of ICLT. The dissemination of this knowledge is crucial and can effectively reach teachers through collegial discussion and informal sharing of ideas as well as more formal settings such as conferences.

This study focused on naturally arising opportunities for ICLT in a classroom without the teacher consciously using the iCLT framework of principles. Future studies might therefore focus on the teacher and student views in classrooms which consciously use intercultural pedagogies. The views of the secondary school CFL teacher in this study appeared to be more supportive of ICLT than those of two other studies examining teacher ICLT practices at tertiary level. Further research more specifically focused on ICLT in CFL might also compare the differing levels of awareness and practices of the intercultural dimension between secondary and tertiary level CFL teachers.

Assessment of intercultural competence in languages and other curriculum areas would no doubt increase teacher and student awareness of its importance. To date there have been some studies both in the field of language teaching (Sercu, 2010) and across the curriculum (Bolstad et al, 2013) which have explored how this might be possible. Although recommendations have been made, the practicalities of assessing the intercultural dimension still remain unclear. Further research in assessing ICLT is necessary before intercultural assessment can become an applied part of school language programmes. 


\section{LIMITATIONS}

This study focuses solely on one CFL classroom with a focus lens on three students and the teacher. One of the student participants was only available for one interview as she was moving to the United States. Data collected from the teacher mainly included classroom observation data. She gave one interview at the end of the study. More interview time and stimulated recall sessions may have provided richer data, though time constraints made this impossible.

Two changes to the stimulated recall process could have strengthened this data collection method. Due to the practicalities of fitting around busy school timetables, stimulated recall sessions took place three to seven days after the classroom observations. Mackey and Gass (2005) recommend that stimulated recall data should be collected as soon as possible in order to best access the short term memory. All efforts were made to avoid researcher interference during stimulated recall sessions. However, in this case time constraints did not allow for participants to select, control, and initiate stimulus episodes as recommended in Mackey and Gass (2005, p. 79).

The data was gathered over three months. Although the data provided an in-depth analysis of one teacher and two student participants, a longer data collection period, with more focus participants or several case studies in different classrooms may have yielded a broader data set. A broader set of data would enable the findings to be applied to a larger number of educational settings.

Though it may be viewed as a limitation that I knew all of the participants, my pre-existing relationships with the participants allowed me to fit into the classroom naturally and enabled participants to feel more comfortable sharing their personal views and experiences during interviews and stimulated recall sessions. My relationship with the teacher and students were taken into consideration during the data collection.

In addition, the data were collected and analysed by one person. Some of my transcripts containing Chinese characters, were informally checked by the participating teacher (a native speaker). However, the reliability of the transcript data could have been further increased if all written Chinese was 
cross-checked by a native speaker. Although this process was overseen by a university lecturer in applied linguistics, coding and analysis of the data could have been further refined with more inter-coder reliability.

\section{CONCLUSION}

Intercultural competence is necessary for people from different cultural backgrounds to live together successfully in today's globalised world. Developing intercultural communicative competence (ICC) in language education is a goal for primary and secondary school students internationally. Although theories relating to the development of ICC in language education are well established in curriculum documents and educational policies, research shows that language teacher application of intercultural pedagogies and theories is not yet widely understood or practised. The literature shows that this is particularly so in the field of CFL.

To bridge this gap, the case study presented in this dissertation sought to better understand the practical application of ICLT theory by exploring naturally arising opportunities for the development of ICC in a CFL classroom using classroom observations, interviews, and stimulated recall. The findings of this study establish that in a classroom not intentionally adopting ICLT, there were occasional natural occurrences of ICLT. However, the findings also indicate that without an explicit inclusion of intercultural pedagogies, ICC is unlikely to be developed in the language classroom context. Furthermore, without an explicit intercultural focus, some students may develop negative cultural stereotypes of the target culture.

This case study prompts the following considerations and recommendations for foreign language teachers, curriculum leaders and researchers who are interested in further practising and researching ICLT. Firstly, teacher awareness and understanding of ICLT needs to increase. For many language students with little experience of the target culture, the teacher is the main source of cultural input, and therefore the teacher's enactment of and approach to culture can positively or negatively influence students. Teacher professional development focusing on ICLT is essential, if the educational goal of 
developing intercultural competence is realistically to be achieved. With more awareness and training in ICLT, teachers are likely to realise that an intercultural dimension could be incorporated into the existing linguistic and cultural activities such as watching films or discussing celebrations.

Secondly, intercultural reflection and comparison need to be regularly included into language classes. Evidence from this study and previous research (Conway \& Richards, 2013; Liddicoat \& Scarino, 2013) show that in language classrooms unaware of ICLT, the inclusion of an explicit intercultural comparative and reflective dimension to language classroom tasks and activities is also often absent. The processes of reflection and comparison are key in developing ICC, as intercultural competence involves developing deeper understanding and awareness of one's own culture(s) in relation to other cultures.

Class activities in this case study did not involve an explicit comparative and reflective dimension. Consequently, though students encountered and engaged with aspects of Chinese culture outside of the classroom, they were not able to connect with and further explore these experiences in the classroom. Without explicit exploration of these experiences in class, students appeared to develop cultural stereotypes and draw uninformed conclusions. In the case of one student, being able to discuss and explore issues in class might have prevented her from developing strong negative feelings about certain aspects of Chinese culture. Explicit class discussions surrounding complex cultural issues may have consequently led to more open and understanding attitudes, thus developing intercultural competence.

Lastly, the intercultural approach may not only promote the development of intercultural competence, but also provide many potential benefits to language education. Findings in this study also revealed that two students felt disconnected from learning CFL. The inclusion of explicit classroom intercultural exploration, comparison and reflection alongside developing linguistic proficiency has the potential to empower students to develop a stronger sense of connection with the target language and culture and subsequently remain interested in learning a language at a higher level. This consideration is significant for foreign language teachers in New Zealand and the 
English-speaking world as student interest in learning languages beyond beginner level remains low.

In a CFL classroom with no formal training in ICLT, this case study revealed many opportunities for the potential inclusion and benefits of intercultural pedagogies. In developing intercultural communicative competence in the language classroom, the inclusion of an explicit reflective dimension to language teaching is particularly important. Increased language teacher awareness and ability to apply ICLT in the classroom is crucial. Successful application of ICLT pedagogies in the language classroom has tremendous scope to develop multilingual, culturally self-aware, interested, open-minded, tolerant and life-long learners.

\section{REFERENCES}

Asia Society, (2015). Global competence. Retrieved from http://asiasociety.org/global-competenceasiasociety.org/globalcompetence, 24 February, 2015.

Bolstad, R., Hipkins, R., \& Stevens, L. (2013). Measuring New Zealand students' international capabilities: An exploratory study. Final report to the Ministry of Education, Wellington, New Zealand: New Zealand Council for Educational Research.

Byram, M. (1997). Teaching and assessing intercultural communicative competence. Clevedon: Multilingual Matters.

Byram, M., Holmes, P. \& Savvides, N. (2015) Guest editorial. The Language Learning Journal, 43(2), 129-130.

Byram, M. (2013). Intercultural communicative competence in foreign language education: questions of theory, practice and research. The Language Learning Journal, 41(3), 251-253. 
Byram, M. (2014). Twenty-five years on - from cultural studies to intercultural citizenship, Language, Culture and Curriculum, 27(3), 209-225.

Byram, M., Nichols, A. \& Stevens, D. (2001). Developing intercultural competence in practice. Clevedon: Multilingual Matters.

Byram, M. \& Parmenter, L. (2012). The common European framework of reference: The globalisation of language education policy. Bristol: Multilingual Matters.

Chang, J. (1991). Wild swans three daughters of China. London: Flamingo.

Chang, P., Mackerras, A. \& Yu, H.C. (1995). Hànyu for beginning students. Melbourne: Longman.

Charmaz, K. (2014). Constructing grounded theory. London: Sage.

Chen, S. (2008). Issues in the teaching of culture in Chinese language education, In P.Duff \& P. Lester (Eds.), Issues in Chinese language education and teacher development, UBC Centre for Research in Chinese Language and Literacy Education (pp.79-88). University of British Columbia Canada.

Chen, G. M. \& Starosta, W. J. (1998). A review of the concept of intercultural awareness, Human Communication, 2(1), 27-54.

Chun, D. M. (2011). Developing intercultural communicative competence through online exchanges. CALICO Journal, 28(2), 1-36. 
Conway, C. \& Richards, H. (2014). Intercultural language learners: Are you providing opportunities for your students to reflect? NZALT Polyglot, 39, 23-25.

Conway, C., Richards, H., Harvey, S., \& Roskvist, A. (2010): Teacher provision of opportunities for learners to develop language knowledge and cultural knowledge. Asia Pacific Journal of Education, 30(4), 449-462.

Conway, C., Richards, H., Harvey, S., \& Roskvist, A. (2012). Professional development for language teachers: Response to a change in learning languages policy. In B. Boufoy-Bastick, (Ed.). Cultures of professional development for teachers: Collaboration, reflection, management and policy. (pp.159-182). Strasbourg, France: Analytrics.

Coperías Aguilar, M. (2007). Dealing with intercultural communicative competence in the foreign language classroom, In E.A. Soler \& M.P.S. Jordà (Eds.), Intercultural language use and language learning, (pp.59-78). Dordrecht: Springer.

Danison, N. (2013). Integrating culture and language in the Chinese as a foreign language classroom: A view from the bottom up, In I. Kecskés (Ed), Research in Chinese as a second language, (pp.81-114), Berlin: De Gruyter Mouton.

Darvin, R. \& Norton, B. (2015). Identity and a model of investment in applied linguistics, Annual Review of Applied Linguistics, 35, 36-56.

Diaz, A. R. (2013). Developing critical languaculture pedagogies in higher education: theory and practice (Vol.25). Bristol: Multilingual Matters.

Duff, P. (2012). How to carry out case study research, In A. Mackey \& S. Gass (Eds.), Research Methods in Second Language Acquisition: A Practical Guide, pp.95-116. Chichester: Wiley-Blackwell.

Erlam, R. (2015). Why the interact standard is good for your language classroom, The New Zealand Language Teacher, 41, 23-33.

East, M. (2008). Learning additional languages in New Zealand schools. Curriculum Matters, 4, 113-133.

East, M. (2009). Promoting positive attitudes towards foreign language learning: a New Zealand initiative. Journal of Multilingual and Multicultural Development, 30(6), 493-507.

East, M. (2012). Addressing the intercultural via task-based language teaching: possibility or problem? Language and Intercultural Communication, 12(1), 56-73. 
East, M. (2015, April 29). Monolingualism - inflexible, insensitive and arrogant, The New Zealand Herald. Retrieved from http://www.nzherald.co.nz/nz/news/article.cfm?c id=1\&objectid=1144 $\underline{0346}$

Ellis, R. (2005). Instructed second language acquisition: A literature review. Wellington, NZ: Ministry of Education.

Friedman, D. (2013). How to collect and analyze qualitative data. In A. Mackey \& S. M. Gass (Eds.), Research methods in second language acquisition: A practical guide (pp.180-200). Wiley-Blackwell.

Gumperz, J. (2005). Interactional sociolinguistics: A personal perspective, In D. Schiffrin, D. Tannen, \& H. Hamiton (Eds), The Handbook of Discourse Analysis (pp. 215-228). Oxford: Blackwell.

Halliday, M. (1990, April). New ways of meaning: A challenge for applied linguistics. Plenary address at the tenth AILA Congress, Thessaloniki, Greece.

Humboldt, W. (1988[1836]). On language: the diversity of human languagestructure and its influence on the mental development of mankind. (Tr. Peter Heath). Cambridge: Cambridge University Press.

Koiso, H., Horiuchi, Y., Tutiya, S., Ichikawa, A., \& Den, Y. (1998). An analysis of turn-taking and backchannels based on prosodic and syntactic features in Japanese map task dialogs. Language and speech, 41(3-4), 295-321.

Kohler, M. (2015). Teachers as mediators in the foreign language classroom. Bristol: Multilingual Matters.

Kramsch, C. (1993). Context and culture in language education. Oxford: Oxford University Press.

Kramsch, C. (2006). The multilingual subject. International Journal of Applied Linguistics, 16(1), 97-110.

Krashen, S. (1982). Principles and practice in second language acquisition. Oxford: Pergamon.

Lo Bianco, J., Liddicoat, A. \& Crozet, C. (1999). Striving for the third place: Intercultural competence through language education. Melbourne: Language Australia.

Liddicoat, A. (2001). Everyday speech as culture: Implications for language teaching. In A. Liddicoat \& C. Crozet (Eds), Teaching languages, teaching cultures (pp.51-78). Melbourne: Language Australia.

Liddicoat, A. (2008). Pedagogical practice for integrating the intercultural in language teaching. Japanese studies, 28(3), 277-290. 
Liddicoat, A. (2011). Language teaching and learning from an intercultural perspective, In E. Hinkel (Ed), Handbook of research in second language teaching and learning, Volume 2, (pp. 837-855). New York: Routledge.

Liddicoat, A. (2014). Pragmatics and intercultural mediation in intercultural language learning. Intercultural Pragmatics, 11(2), 259-273.

Liddicoat, A. \& Crozet, C. (2001). Teaching languages, teaching cultures. Melbourne: Language Australia.

Liddicoat, A. \& Scarino, A. (2010). Eliciting the intercultural in foreign language teaching at school, In A. Paran \& L. Sercu (Eds.), Testing the untestable in language education (pp. 52-71). Bristol: Multilingual Matters.

Liddicoat, A. \& Scarino, A. (2013). Intercultural language teaching and learning. Chichester: Wiley-Blackwell.

Mackey, A. \& Gass, S. (2005). Second Language Research: Methodology and Design, New York: Routledge.

Ministry of Education. (2007). The New Zealand curriculum. Wellington, NZ: Learning Media.

Newton, J. (Forthcoming). Teaching English for intercultural spoken communication, In W. A. Renandya \& H.P. Widodo (Eds.), English language teaching today: Linking theory and practice. New York: Springer.

Newton, J. (2014, July). Teaching and learning interculturally: principles to practice and back again. Keynote address at the NZALT (New Zealand Association of Language Teachers) 40th Anniversary Conference, Palmerston North, New Zealand.

Newton, J. (2014, November). Fostering intercultural literacy in New Zealand through language education. Paper presented at ALANZ 2014, Auckland, New Zealand.

Newton, J., Yates, E., Shearn, S. \& Nowitzki, W. (2010). Intercultural communicative language teaching: Implications for effective teaching and learning. (pp. 1-90). Report to the Ministry of Education. Retrieved from http://www.educationcounts.govt.nz/publications/curriculum/76637/in trodcution, 2 December, 2014.

Norton Peirce, B. (1995). Social identity, investment, and language learning. TESOL Quarterly, 29(1), 9-31.

Nguyen, M. (2014). Preservice EAL teaching as emotional experiences: Practicum experience in an Australian secondary school. Australian Journal of Teacher Education, 39(8), 62-84. 
Oranje, J. (2013, November). Teaching culture in language classes at New Zealand secondary schools: Use of cultural portfolio projects as an intercultural communicative activity. Paper presented at ALANZ 2013, Wellington, New Zealand.

Oranje, J. (2014, November). Intercultural communicative language teaching: Using teacher cognitions to bridge theory and practice. Paper presented at the IALIC conference, Aveiro, Portugal.

Orton, J. (2011). Educating Chinese language teachers - Some fundamentals, In L. Tsung \& K. Cruickshank (Eds.), Teaching and Learning Chinese in Global contexts, (pp.151-164). London: Continuum.

Perry, L. \& Southwell, L. (2011). Developing intercultural understanding and skills: models and approaches. Intercultural Education, 22(6), 453-466.

Scrimgeour, A. \& Wilson, P. (2009). International curriculum for Chinese language education. Babel, 43(2), 35.

Sercu, L. (2004). Intercultural communication competence in foreign language education: Integrating theory and practice, In O. St John, K. van Esch \& E. Schalkwijk (Eds.), New insights into foreign language learning and teaching, (pp.115-130). Frankfurt: Peter Lang.

Sercu, L. (2006). The foreign language teacher and intercultural competence teacher: the acquisition of a new professional identity. Intercultural Education, 17(1), 55-72.

Sercu, L. (2010). Assessing intercultural competence: More questions than answers. In A. Paran \& L. Sercu (Eds.), Testing the untestable in language education (pp. 17-34). Bristol: Multilingual Matters.

Sfard, A. (1998). On two metaphors for learning and the dangers of choosing just one. Educational Researcher, 27, 4-13.

Skene, C. (2013). Investigating reciprocal meaning-making as an element of intercultural language learning in the languages classroom. Babel, 48(2), 48-58.

Statistics New Zealand. (2013). New Zealand has more ethnicities than the world has countries. Retrieved from http://www.stats.govt.nz/Census/2013-census/data-tables/totals-bytopic-mr1.aspx, 5 December, 2015.

Stubbe, M., Lane, C., Hilder, J., Vine, E., Vine, B., Marra, M., Holmes, J. \& Weatherall, A. (2003). Multiple discourse analyses of a workplace interaction. Discourse studies, 5(3), 351-388.

Swain, M. (2006). Languaging, agency, and collaboration in advanced language proficiency. In H. Byrnes (Ed.), Advanced Language Learning: The 
Contribution of Halliday and Vygotsky (pp.95-108). London: Continuun.

Swain, M. \& Lapkin, S. (1998). Interaction and second language learning: two adolescent French immersion students working together.

Modern Language Journal 82(3), 320-337.

Tannen, D, Kendall, S. \& Gordon, C. (2007). Family Talk: Discourse and identity in four American families. New York: Oxford University Press.

Tian, M. \& Lowe, A. (2014). Intercultural identity and intercultural experiences of American students in China. Journal of Studies in International Education, 18(3), 281-297.

Te Kete Ipurangi, Ministry of Education, (2015). What are international capabilities. Retrieved from http://nzcurriculum.tki.org.nz/Curriculumresources/International-capabilities/About, 24 February, 2015.

Te Kete Ipurangi, Ministry of Education, (2015). Learning Languages: Learning Area Structure. Retrieved from http://nzcurriculum.tki.org.nz/The-New-Zealand-Curriculum/Learningareas/Learning-languages/Learning-area-structure, 20 February, 2015.

Tsung, L. \& Cruickshank, K. (2011). Teaching and Learning Chinese in Global contexts. London: Continuum.

Wong, K. (2008). 4P's of cultural pedagogy: A new paradigm for the cultural dimension in Chinese language instruction. Journal of the Chinese Language Teachers Association, 43(3), 1-24.

Xing, J. (2006). Teaching and learning Chinese as a foreign language: $A$ pedagogical grammar. Hong Kong: Hong Kong University Press.

Yang, J. H. (2009). Laihua liuxuesheng kuawenhua shiying de wenti yanjiu (Research on cross-cultural adaption of intercultural students in China). Shanghai, China: Shanghai Academy of Social Sciences Press.

Yu, L. (2008). Exploring learners' intercultural behaviors: Applying the performed culture approach in Chinese language pedagogy. Journal of the Chinese Language Teachers Association, 43(3), 121-145.

Zhou, W. \& Li, G. (2014). Chinese language teachers' expectations and perceptions of American students' behavior: Exploring the nexus of cultural differences and classroom management. System, 49, 17-27. 


\section{Appendix 1}

\section{Student questions for the final written reflection}

What do you enjoy about learning Chinese

What knowledge and skills have you gained from learning Chinese (linguistic and non-linguistic)?

Would you like to learn more about Chinese culture?

Are you happy with the approach taken?

Would you like to have more time for reflection and discussion? 


\section{Appendix 2}

\section{Questions for the final interview with the teacher}

Can you describe your view or philosophy on the role of culture in the foreign language classroom?

In your teacher training or in any professional development you have completed, what focus on culture were you given?

How do you teach culture?

In your cultural sessions, what types of activities do you do?

What aspects of Chinese culture do you believe are important for the students to learn? Why do you cover these aspects?

As a native speaker teacher, how do you relate your culture to the students? 


\section{Appendix 3}

\section{Transcription conventions}

$\begin{array}{ll}((\text { words })) & \begin{array}{l}\text { Double parentheses enclose transcriber's comments, in } \\ \text { italics. }\end{array} \\ \text { /words/ } & \text { Slashes enclose uncertain transcription. } \\ \text { carriage return } & \text { Each new line represents and intonation unit. } \\ \rightarrow & \text { An arrow indicates that the intonation unit continues to the } \\ & \text { next line. } \\ - & \text { A Dash indicates a truncated intonation unit. } \\ - & \text { A hyphen indicates a truncated word or adjustment within } \\ & \text { an intonation unit, e.g. repeated word, false start. } \\ ? & \text { A question mark indicates a relatively strong rising } \\ & \text { intonation. } \\ \text { A period indicates a falling, final intonation. } \\ \ldots & \text { A comma indicates a continuing intonation. } \\ : & \text { Dots indicate silence (more dots indicate a longer silence). } \\ \text { CAPS } & \text { A colon indicates an elongated sound. } \\ <\text { laughs }> & \text { Capitals indicate emphatic stress. } \\ & \text { Angle brackets enclose descriptions of vocal noises, e.g., } \\ <\text { laughs, coughs. } \\ \text { Angle brackets enclose descriptions of the manner in which } \\ \text { an utterance is spoken, e.g. high-pitched, laughing, } \\ \text { incredulous. }\end{array}$

(Direct quotation, Tannen et al, 2007, pp. xiii - xiv) 